\title{
AFRL-RQ-WP-TR-2015-0083
}

\section{SCIENTIFIC ARTICLES ON MAGNETIC MATERIALS AND APPLICATIONS RESEARCH FROM 2006 - 2014}

John C. Horwath

Mechanical and Thermal Systems Branch

Power and Controls Division

MARCH 2015

Final Report

Approved for public release; distribution unlimited.

See additional restrictions described on inside pages

STINFO COPY

AIR FORCE RESEARCH LABORATORY

AEROSPACE SYSTEMS DIRECTORATE

WRIGHT-PATTERSON AIR FORCE BASE, OH 45433-7541

AIR FORCE MATERIEL COMMAND

UNITED STATES AIR FORCE 


\section{NOTICE AND SIGNATURE PAGE}

Using Government drawings, specifications, or other data included in this document for any purpose other than Government procurement does not in any way obligate the U.S. Government. The fact that the Government formulated or supplied the drawings, specifications, or other data does not license the holder or any other person or corporation; or convey any rights or permission to manufacture, use, or sell any patented invention that may relate to them.

This report was cleared for public release by the USAF 88th Air Base Wing (88 ABW) Public Affairs Office (PAO) and is available to the general public, including foreign nationals.

Copies may be obtained from the Defense Technical Information Center (DTIC) (http://www.dtic.mil).

AFRL-RQ-WP-TR-2015-0083 HAS BEEN REVIEWED AND IS APPROVED FOR PUBLICATION IN ACCORDANCE WITH ASSIGNED DISTRIBUTION STATEMENT.

*//Signature//

JOHN C. HORWATH

Electrical Engineer

Mechanical and Thermal Systems Branch

Power and Controls Division
//Signature//

THOMAS L. REITZ, Technical Advisor Mechanical and Thermal Systems Branch

Power and Controls Division

//Signature//

JOHN G. NAIRUS

Chief Engineer

Power and Controls Division

Aerospace Systems Directorate

This report is published in the interest of scientific and technical information exchange, and its publication does not constitute the Government's approval or disapproval of its ideas or findings.

*Disseminated copies will show “//Signature//” stamped or typed above the signature blocks. 


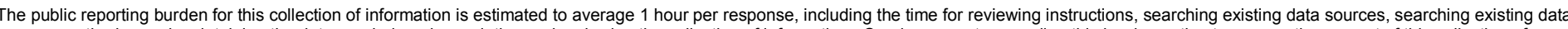

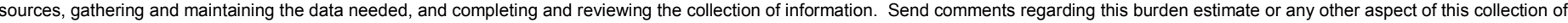

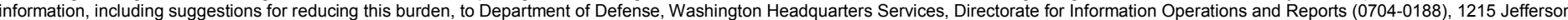

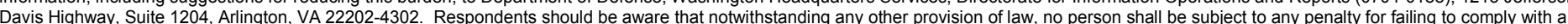
collection of information if it does not display a currently valid OMB control number. PLEASE DO NOT RETURN YOUR FORM TO THE ABOVE ADDRESS
1. REPORT DATE (DD-MM-YY)
2. REPORT TYPE
March 2015
Final
3. DATES COVERED (From - To)
01 October 2006 - 01 October 2014

4. TITLE AND SUBTITLE

SCIENTIFIC ARTICLES ON MAGNETIC MATERIALS AND APPLICATIONS

RESEARCH FROM 2006 - 2014 5a. CONTRACT NUMBER

In-house

5b. GRANT NUMBER

5c. PROGRAM ELEMENT

NUMBER

62203F

6. AUTHOR(S)

John C. Horwath

5d. PROJECT NUMBER

3145 5e. TASK NUMBER

$\mathrm{N} / \mathrm{A}$

5f. WORK UNIT NUMBER

Q0JE

7. PERFORMING ORGANIZATION NAME(S) AND ADDRESS(ES)

Mechanical and Thermal Systems Branch (AFRL/RQQM)

Power and Controls Division

Air Force Research Laboratory, Aerospace Systems Directorate

Wright-Patterson Air Force Base, OH 45433-7541

Air Force Materiel Command, United States Air Force

9. SPONSORING/MONITORING AGENCY NAME(S) AND ADDRESS(ES)

Air Force Research Laboratory

Aerospace Systems Directorate

Wright-Patterson Air Force Base, OH 45433-7541

Air Force Materiel Command

United States Air Force

8. PERFORMING ORGANIZATION REPORT NUMBER

AFRL-RQ-WP-TR-2015-0083

10. SPONSORING/MONITORING AGENCY ACRONYM(S)

AFRL/RQQM

11. SPONSORING/MONITORING AGENCY REPORT NUMBER(S)

AFRL-RQ-WP-TR-2015-0083

12. DISTRIBUTION/AVAILABILITY STATEMENT

Approved for public release; distribution unlimited.

13. SUPPLEMENTARY NOTES

PA Case Number: 88ABW-2015-1932; Clearance Date: 15 Apr 2015.

14. ABSTRACT

This program addresses basic scientific and engineering issues related to the development of power magnetic

technologies. Specific research topics are addressed to support Air Force applications. The goals and expected impact of this work are to reduce the weight, heat loss, and volume of AF systems, and also to improve performance or enable new capabilities. As the development of magnetic technologies progress with time, these goals are being reached very significantly.

Specific subtopics and approaches to be emphasized in this work include: study and development of magnetic tape cores, modeling and building of permanent magnet assemblies, research on exchange spring magnets, and modeling and testing of inductors.

15. SUBJECT TERMS

magnetic materials, inductors, high power electronics, high power density, generator, magnetic assemblies, rare earth magnets

\begin{tabular}{|c|c|c|c|c|c|}
\hline 16. $S E$ & & & 17. LIMITATION & 18. NUMBER & IF OF RESPONSIBIF PER \\
\hline $\begin{array}{l}\text { a. REPORT } \\
\text { Unclassified }\end{array}$ & $\begin{array}{l}\text { b. ABSTRACT } \\
\text { Unclassified }\end{array}$ & $\begin{array}{l}\text { c. THIS PAGE } \\
\text { Unclassified }\end{array}$ & $\begin{array}{c}\text { OF ABSTRACT: } \\
\text { SAR }\end{array}$ & $\begin{array}{l}\text { OF PAGES } \\
44\end{array}$ & $\begin{array}{l}\text { John C. Horwath } \\
\text { 19b. TELEPHONE NUMBER (Include Area Code) } \\
\text { N/A }\end{array}$ \\
\hline
\end{tabular}




\section{TABLE OF CONTENTS}

Section Page

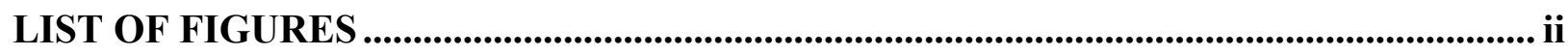

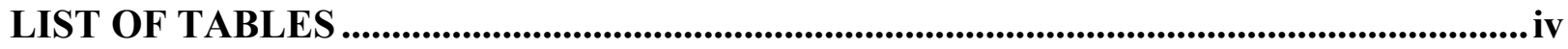

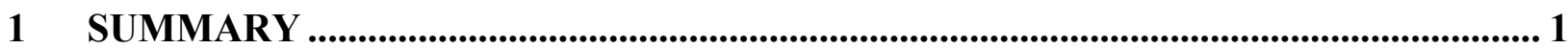

1.1 Executive Summary of Progress and Milestones/Lessons Learned ............................ 1

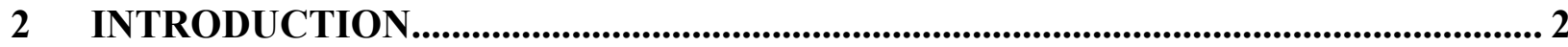

3 HARD (PERMANENT) MAGNETS ......................................................................... 3

3.1 Rare Earth Magnets.......................................................................................... 3

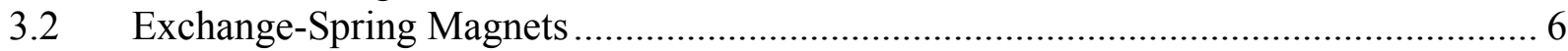

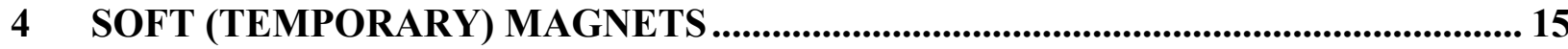

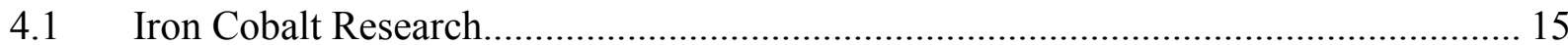

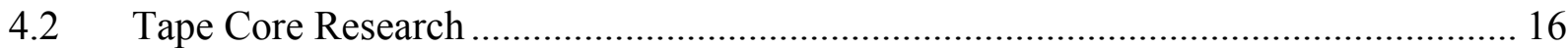

4.3 Basic Science of Soft Magnetic Materials ............................................................. 18

5 APPLICATIONS AND MODELING ...................................................................... 21

$5.1 \quad$ Permanent Magnet Solenoids ......................................................................... 21

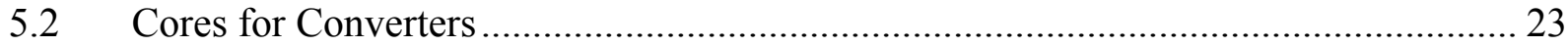

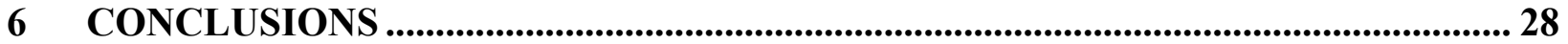

7 RECOMMENDATIONS................................................................................................ 29

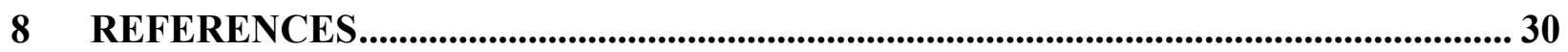




\section{LIST OF FIGURES}

Figure

Page

Figure 1. Demagnetization Curves vs. the Typical Flake Thickness...........................................

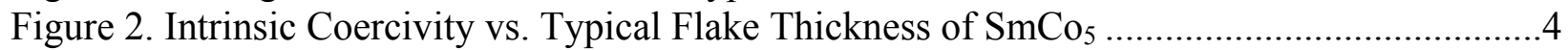

Figure 3. Differential Scanning Calorimetry Curves for $\mathrm{SmCo}_{5}$ Prepared with Different

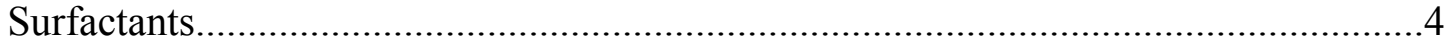

Figure 4. SEM Images of the Flakes Clumped at the Bottom of the Solvent ...............................5

Figure 5. Magnetization Curves of a $\mathrm{PrCo}_{5}$ Powder Sample........................................................6

Figure 6. Nanocomposite Spring Exchange MH Loops ............................................................

Figure 7. Demagnetization Curves of Bulk Sm-Co/ $\alpha-\mathrm{Fe}$ Magnets with Different Amounts of Fe Addition and Maximum Energy Product vs. Fe Content..............................................8

Figure 8. Demagnetization Curves for SmCo Magnet and Sm-Co-Fe Composite Magnets

Prepared from Blended and Milled Powder..............................................................9

Figure 9. Demagnetization Curves of Bulk Sm-Co/ $\alpha-(\mathrm{Fe}, \mathrm{Co})$ Magnets as a Function of Milling

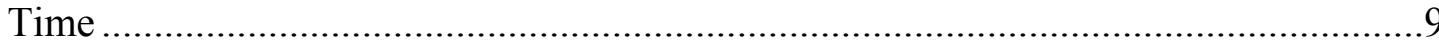

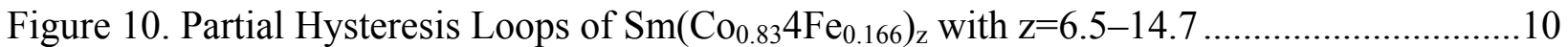

Figure 11. Magnetic Properties of Sm(Co0.834Fe0.166)z vs. Effective z (28\% soft phase for

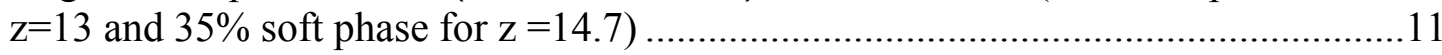

Figure 12. Effect of Fluorine Content on Magnetic Properties of $\operatorname{Sm}\left[\left(\mathrm{Co}_{0.7} \mathrm{Fe}_{0.3}\right)_{1-\mathrm{y}} \mathrm{Fy}\right]_{13}$ with y $=0,0.04$, and 0.08

Figure 13. Demagnetization Curves and Magnetic Properties of Melt-spun $\mathrm{Sm}($ CobalFe0.3ZrxB0.04)10 Alloys with $\mathrm{x}=0.02$ to 0.05

Figure 14. Demagnetization Curves (a) and (b), $\mathrm{H}_{\mathrm{k}} / \mathrm{H}_{\mathrm{c}}$ ratio (c), and $\mathrm{BH}_{\max }(\mathrm{d})$ of Bulk Magnets Nos. 1 to 4 after Hot Pressing (HP) and Hot Deformation (HD)

Figure 15. Demagnetization Curves of the Bulk La-Co Magnets

Figure 16. Yield Strengths of $750{ }^{\circ} \mathrm{C}$ Hot Isostatic Pressed Materials for Given Annealing and Ball Milling Conditions

Figure 17. Thermomagnetic $\mathrm{M}(\mathrm{T})$ Plots of $\mathrm{Fe}_{68.8} \mathrm{Co}_{17.2} \mathrm{Hf}_{7} \mathrm{Cu}_{1} \mathrm{~B}_{6}$ and $\mathrm{Fe}_{69.6} \mathrm{Co}_{17.4} \mathrm{Hf}_{7} \mathrm{~B}_{6}$ Alloys Measured under an Applied Field of $1 \mathrm{kOe.}$

Figure 18. Magnetization as a Function of Temperature from Vibrating Sample Magnetometry and Results from Differential Scanning Calorimetry

Figure 19. Initial AC Permeabilities as a Function of Frequency for the FeCoTaB Sample Annealed at $\mathrm{Tx} 1=551.8 \mathrm{C}$ for increasing anneal times.

Figure 20. Vibrational Density of States for FeCoCrNi from Inelastic Scattering of Neutrons and X-rays

Figure 21. Phonon Density of State Curves for Disordered and Ordered $\mathrm{Fe}_{0.50} \mathrm{Co}_{0.50}$ Alloys.......19

Figure 22. Phonon Density of State Curves for Fe, V and Fe-V Alloys...................................20

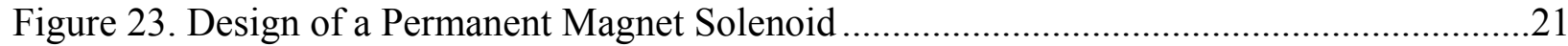

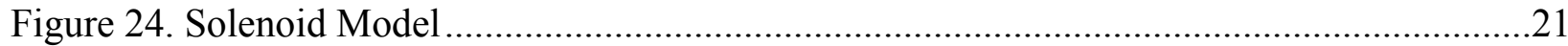

Figure 25. Ratio of the $\mathrm{Bz}$ over the $\mathrm{Bz}(600 \%)$ vs. Padding $\%$ for the Three Solenoids $\left(\beta_{1}=\right.$

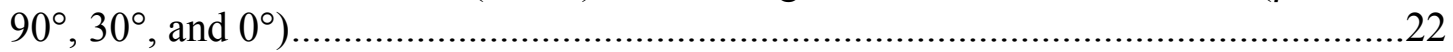

Figure 26. Magnetic Field Uniformity ..............................................................................22

Figure 27. Magnet Assembly with an Inner Bore of $27 \mathrm{~cm}$ and Support Stand .......................23

Figure 28. Circuit of an Interleaved Boost dc-dc Converter..............................................23

Figure 29. Winding Configuration of the Coupled Inductors ...............................................24

ii

Approved for public release; distribution unlimited. 
Figure 30. Pickup Coil Location for the Coupled Inductors.

Figure 31. Experimental Inductor Built Using Two Sets of Metglas AMCC20 C Cores ............25

Figure 32. DC-DC Boost Converter Circuit .............................................................................26

Figure 33. Loss Data Comparison ..................................................................................26

Figure 34. Power Loss Density vs. Pre-magnetization Fields $\left(\mathrm{H}_{\mathrm{DC}}\right.$ fields) for 150, 100, and 50 $\mathrm{kHz}$ Experimental Data. 


\section{LIST OF TABLES}

Table $\quad$ Page

Table 1. Work Unit Papers Published in Magnetic Materials and Applications ...........................2

Table 2. Compositions for Copper Substitution Studies........................................................13

Table 3. Yield Strength Values of FeCoV and FeCoVNb Alloys Measured at Room

Temperature and $482{ }^{\circ} \mathrm{C}$ as a Function of Oxidation Time ......................................16

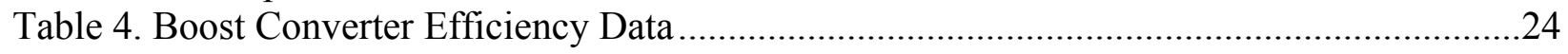

Table 5. Calculated and Simulated AC Flux ........................................................................25 


\section{FOREWORD}

This report summarizes the in-house research efforts for magnetic materials and applications of the AFRL/RQQM team, covering both 6.1 and 6.2 research efforts for an 8-year period of October 2006 to October 2014. The research output of this team was significant with over 20 scientific publications. It is not reasonable to comprehensively cover such a large amount of material in a single report, so a synopsis and summary is provided instead. An introduction is given to the major research topics covered and publication references are provided for the research output that was made publically available. 


\section{PREFACE}

The author would like to especially thank Dr. Ali Sayir and The Air Force Office of Scientific Research (AFOSR) and the Power and Controls Division of the Aerospace Systems Directorate (AFRL/RQQ), for their generous and consistent support of this work.

The author also thanks the current and former team members and collaborators that did the research for this effort and that this report references and highlights. The author specifically thanks Zafer Turgut, Yuhui Shen, Serhiy Leontsev, Meiqing Huang, Christina Chen, Hiroyuki Kosai and Matt Lucas for their consistently impressive work.

Magnetic components and electromachines are essential to most aerospace systems. The drive for lighter, smaller, more powerful and more efficient magnetic components and electromachines has been the impetus for this work unit.

The Department of Defense has recognized the need for advanced magnetic materials and devices and has supported research in these areas. This support has led to some major discoveries. For example, the energy product of permanent magnets has greatly increased since the 1960s due to two key discoveries by Department of Defense researchers. Air Force researchers Strnat and Hoffer developed the first rare earth cobalt magnets in the 1960s [1]. Navy researchers Koon and Das developed the first rare earth-iron-boron magnets in the early 1980s [2]. 


\section{SUMMARY}

\subsection{Executive Summary of Progress and Milestones/Lessons Learned}

During the years FY06-FY14 various magnetic materials and magnetic applications were investigated. These magnetic materials and magnetic applications were for power applications. These power applications include inductors, transformers, electric motors, generators, actuators and converters. Being non-power areas, this effort did not include research in sensors or data storage. Soft (temporary) and hard (permanent) magnetic materials were part of this research effort. Soft magnetic research included iron cobalt research, tape core research, and research on the basic science of soft magnetic materials. Hard magnetic material research focused on rare earth powder or flake preparation, bulk rare earth magnet fabrication, and exchange-spring magnet research. The last area of this report involves applications of magnetic materials. Two applications are described. The design, modeling and building of a permanent magnet solenoid is discussed. Second, the performance of magnetic cores for converters is discussed.

Collaborations proved very useful in this project. A cross directorate AFOSR lab task with AFRL/RX led to much high level basic science on magnetic alloys being done. Another cross directorate collaboration with AFRL/RDHP led to the development, patenting and fabrication of a permanent magnet solenoid. A cross branch effort with AFRL/RQQE led to applied research on loss and DC bias measurements for booster converter cores. 


\section{INTRODUCTION}

This work unit was established with three initial objectives. The first objective for this effort was soft magnetic iron cobalt development for a potential rotor of a superconducting generator program. The small-scale iron cobalt work was successful and is described in Section 3.1 of this report. The second objective was to develop core-shell soft magnetic materials with high magnetization and high temperature capability. This work transitioned to tape core work and is described in Section 3.2 of the report. The third objective was to develop exchange-spring hard magnets, which could lead to an ultimate $2 \mathrm{X}$ increase in energy product compared to state-ofthe-art permanent magnets. Exchange-spring magnet work is described in Section 2.2.

Besides the original objectives of the work unit, other areas were worked on as needed for collaborations, or for work on more basic magnetic material research, or for work on exchangespring magnet precursor materials. The collaborative work included efforts on permanent magnet solenoids and converter core performance. This work is described in Sections 4.1 and 4.2 respectively. Basic magnetic material research focused on high-entropy magnetic alloys and phonon densities of states of magnetic alloys. This work is described in Section 3.3

Many papers were published by researchers and collaborators of this work unit. Only first authors directly involved with this work unit or major collaborators of this work unit are included in the Table 1.

Table 1. Work Unit Papers Published in Magnetic Materials and Applications

\begin{tabular}{|l|c|c|c|c|c|c|c|c|c|c|} 
Research Areas & 2007 & 2008 & 2009 & 2010 & 2011 & 2012 & 2013 & 2014 & \multicolumn{1}{c|}{ Totals } \\
\hline Rare Earth Magnets & & & & 1 & 3 & 1 & 1 & & 6 \\
\hline Exchange-Spring Magnets & & 1 & 1 & & 1 & 1 & 1 & & 5 \\
\hline Iron Cobalt Research & & 1 & 1 & & & & & & 2 \\
\hline Tape Core Research & & & & 1 & 1 & & & & 2 \\
\hline Basic Science & & & 2 & 2 & 1 & 2 & & & 7 \\
\hline Permanent Magnet Solenoids & & & & & 1 & 1 & & & 2 \\
\hline Cores for Converters & & & 1 & & & & 1 & & 2 \\
\hline Totals & 0 & 2 & 5 & 4 & 7 & 5 & 3 & 0 & 26 \\
\hline
\end{tabular}

Major breakthroughs that bring totally new magnetic systems to electrical power engineering are very hard and relatively rare. Perhaps just four breakthroughs in power magnetic materials have occurred since the 1930s. Ferrites were initially developed in Holland during the 1930s and 1940s [1]. Amorphous tapes or sheets for power transformers were developed by AlliedSignal during the 1970s [3]. Rare earth cobalt permanent magnets were first developed at the precursor to the Air Force Research Laboratory in the 1960s [1]. The first rare earth-iron-boron magnets were developed at the Naval Research Laboratory in the early 1980s [2].

If such breakthroughs do occur they typically transition to commercial success quickly due to the importance of magnetic materials to modern industrial economies. Besides such breakthroughs the design space of optimizing existing magnetic systems for specific applications is large. Additionally, even given a specific magnetic material, device design can be also be optimized. This work unit had efforts in all three of the research levels just discussed. 


\section{HARD (PERMANENT) MAGNETS}

\subsection{Rare Earth Magnets}

Rare earth magnets made of a rare earth typically samarium or neodymium with cobalt or iron have the greatest energy products of any room temperature permanent magnets. The existing neodymium iron boron system and samarium cobalt system are of interest to research improved properties or as the hard magnetic component of exchange-spring magnets. In particular, samarium cobalt magnets and precursor powders or flakes were researched [4] [5] [6] [7]. Praseodymium rare earth magnets were also explored [8] [9].

The samarium cobalt research included both efforts on flake or powder preparation as well as efforts on bulk magnets. Flake and powder efforts involved various ball milling procedures on samarium cobalt. Flake thickness and its effect on performance were investigated [4]. Second quadrant curves were heavily affected by flake thickness as shown in Figure 1. In this work outstanding coercivity values up to $21 \mathrm{kOe}$ were obtained for $\mathrm{SmCo}_{5}$ flakes. Coercivity as a function of flake thickness is shown in Figure 2 [7].

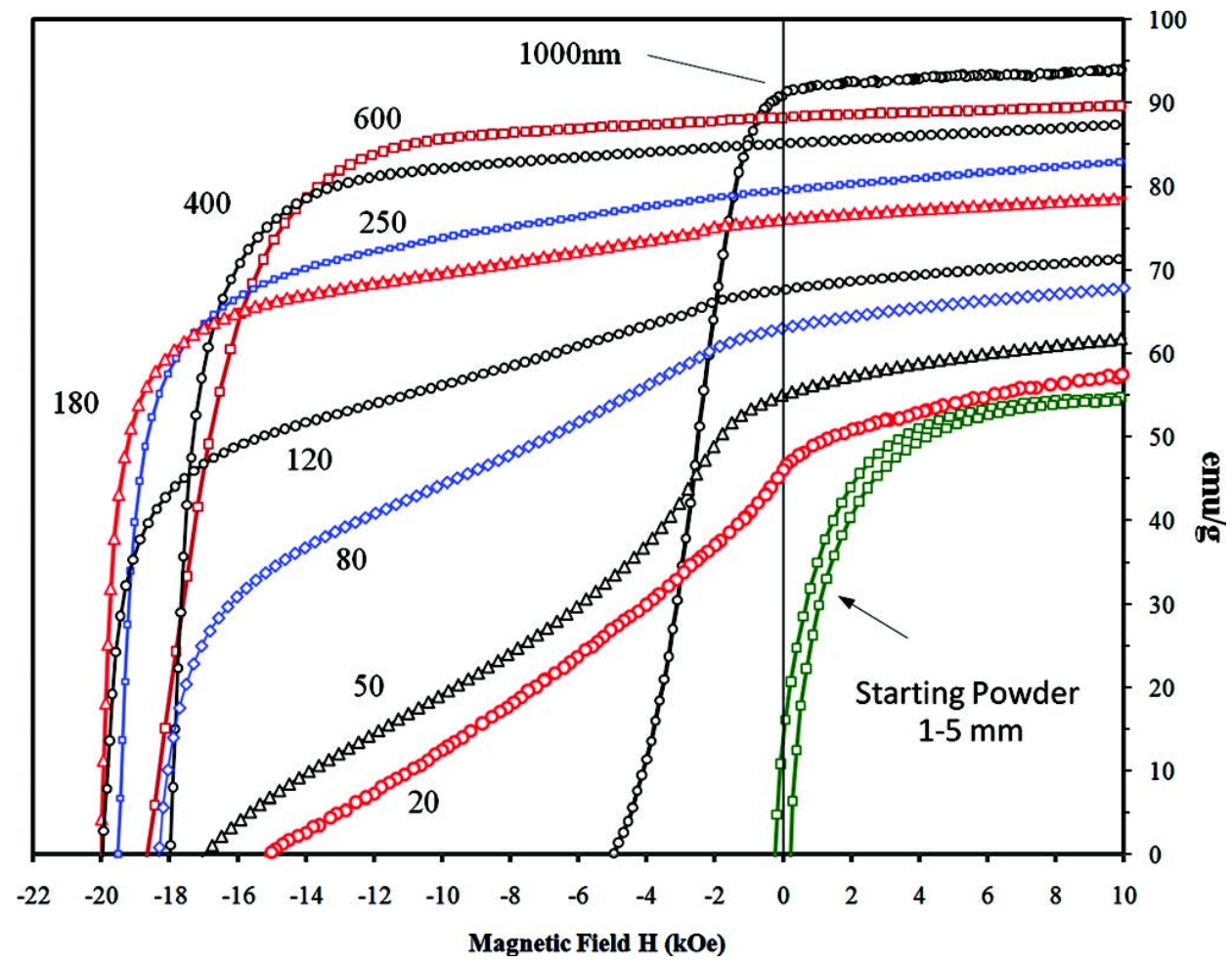

Figure 1. Demagnetization Curves vs. the Typical Flake Thickness 


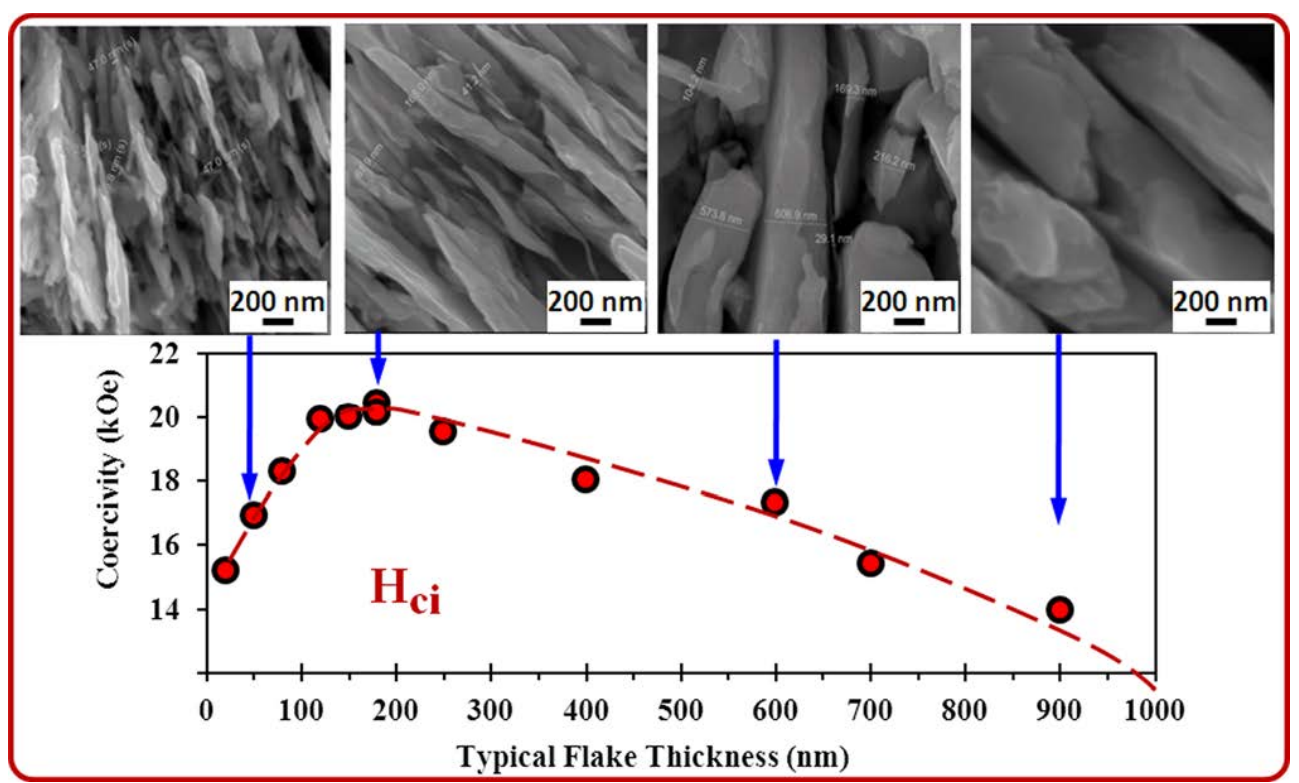

Figure 2. Intrinsic Coercivity vs. Typical Flake Thickness of $\mathrm{SmCo}_{5}$

Much of the flake preparation was done by surfactant assisted ball milling. Studies were done on surfactants of varying molecular weights and on surfactant removal [5] [6]. Differential scanning calorimetry showed that surfactants of lower molecular weight were driven off of the samarium cobalt samples Figure 3.

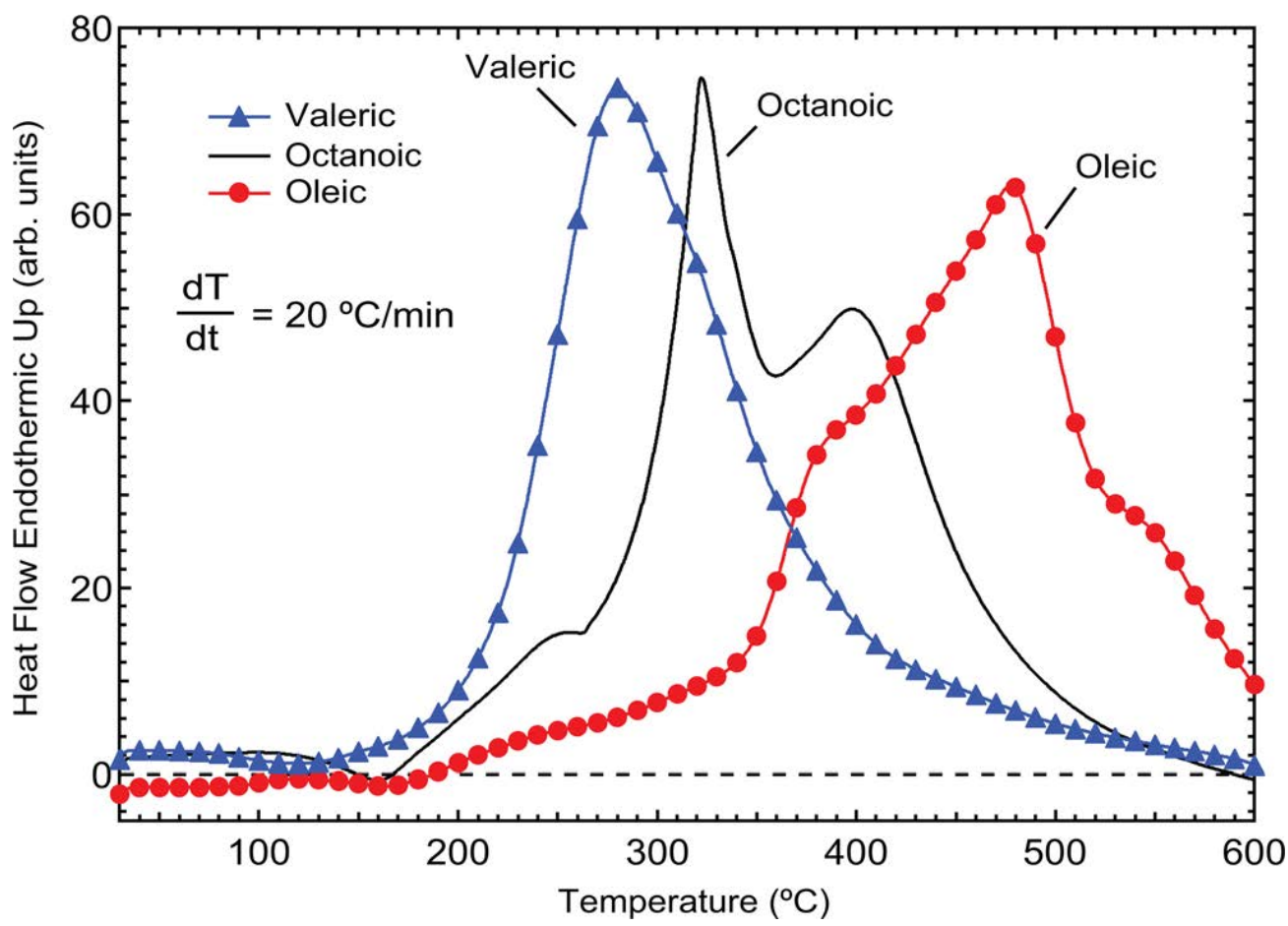

Figure 3. Differential Scanning Calorimetry Curves for $\mathrm{SmCo}_{5}$ Prepared with Different Surfactants 
Praseodymium cobalt work also focused on surfactant assisted ball milling for flake production and consolidation experiments [8] [9]. Figure 4 shows the $\mathrm{PrCo}_{5}$ nanoflakes with thicknesses around tens to hundreds of nanometers and widths of a few micrometers.

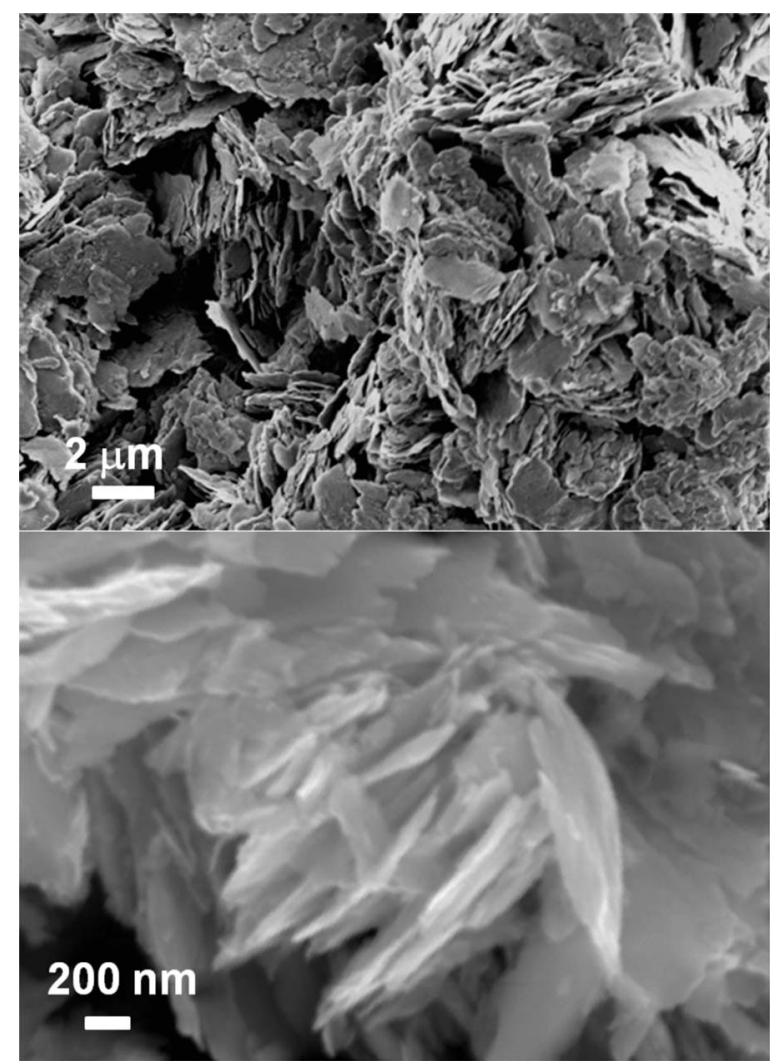

Figure 4. SEM Images of the Flakes Clumped at the Bottom of the Solvent

Some anisotropy was developed in these $\mathrm{PrCo}_{5}$ flakes as shown in Figure 5 by comparing measurements of an oriented sample by vibrating sample magnetometer in parallel and perpendicular directions. However the hot-pressed bulk magnets lost coercivity due to oxidation. 


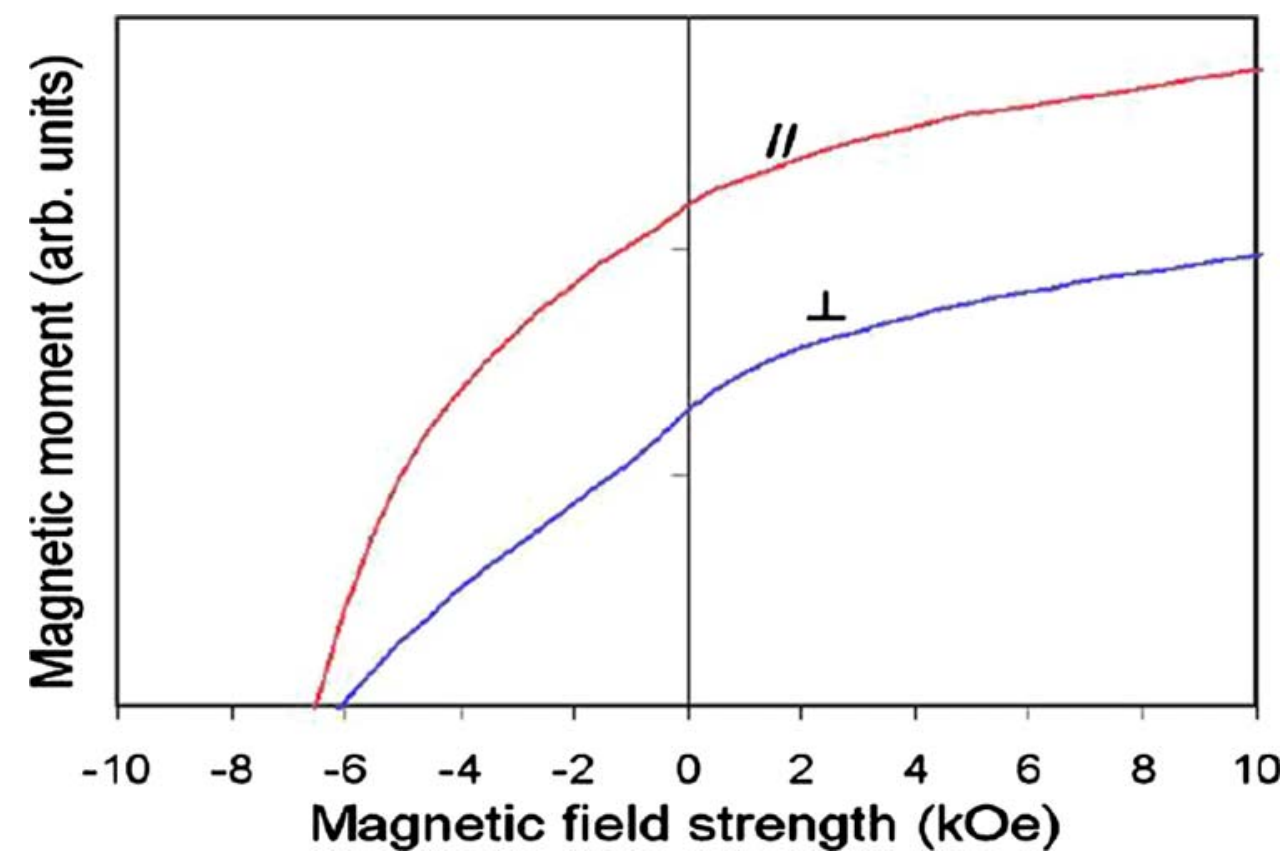

Figure 5. Magnetization Curves of $\mathrm{PrCo}_{5}$ Powder Sample

\subsection{Exchange-Spring Magnets}

The general reasoning to consider a nanocomposite of hard and soft phases is that a large increase in energy product may be attainable [10]. The coercivity of the hard phase is combined with the high magnetization of the soft phase to make a theoretically stronger magnet as shown in Figure 6. 


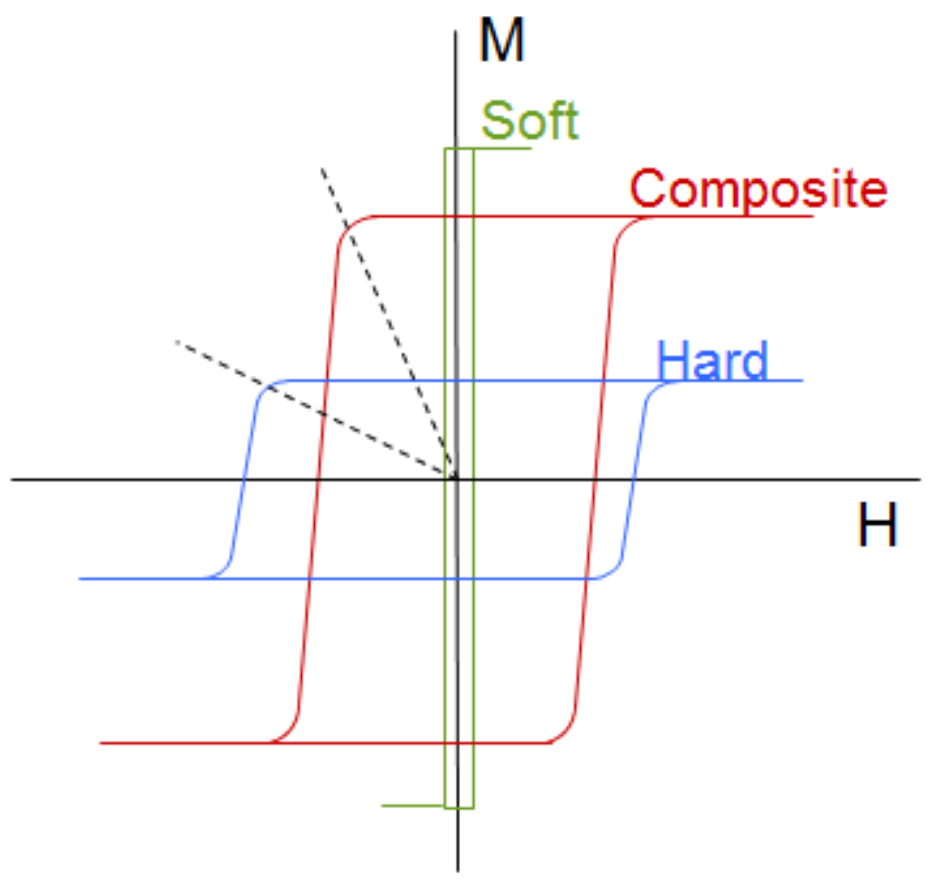

Figure 6. Nanocomposite Spring Exchange MH Loops

Five journal articles were published on exchange-spring magnets. Four of the journal articles were on samarium cobalt nanocomposites [11] [12] [13] [14]. The fifth article was on a $\mathrm{LaCo}_{5} / \mathrm{LaCo}_{13}$ nanocomposite [15]. Bulk Sm-Co/ $\alpha-\mathrm{Fe}$ nanocomposite magnets were made by high energy ball milling and subsequent quick hot-pressing. Soft phase amount and type were investigated. The effect of Fe soft phase content on the magnetic properties of the final bulk samples was examined. Increasing the Fe content significantly increased the saturation magnetization but at the cost of reduced coercivity (Figure 7). The optimum Fe addition for the highest maximum energy product was determined to be fifteen weight percent. Besides pure Fe a $\mathrm{Fe}-\mathrm{Co}-\mathrm{V}$ powder was also studied as a soft phase addition. The results indicated that $\mathrm{Fe}-\mathrm{Co}-\mathrm{V}$ powder was more readily alloyed with the Sm-Co phase during the milling procedure. This undesirable alloying was not as evident with Fe as the soft phase. For the final bulk magnets, nanoscale Fe particles existed in Sm-Co matrix with pure Fe addition, but with Fe-Co-V addition the soft phase particles were undetectable. Also, two methods for adding soft phase Fe into hard phase SmCo were utilized. 


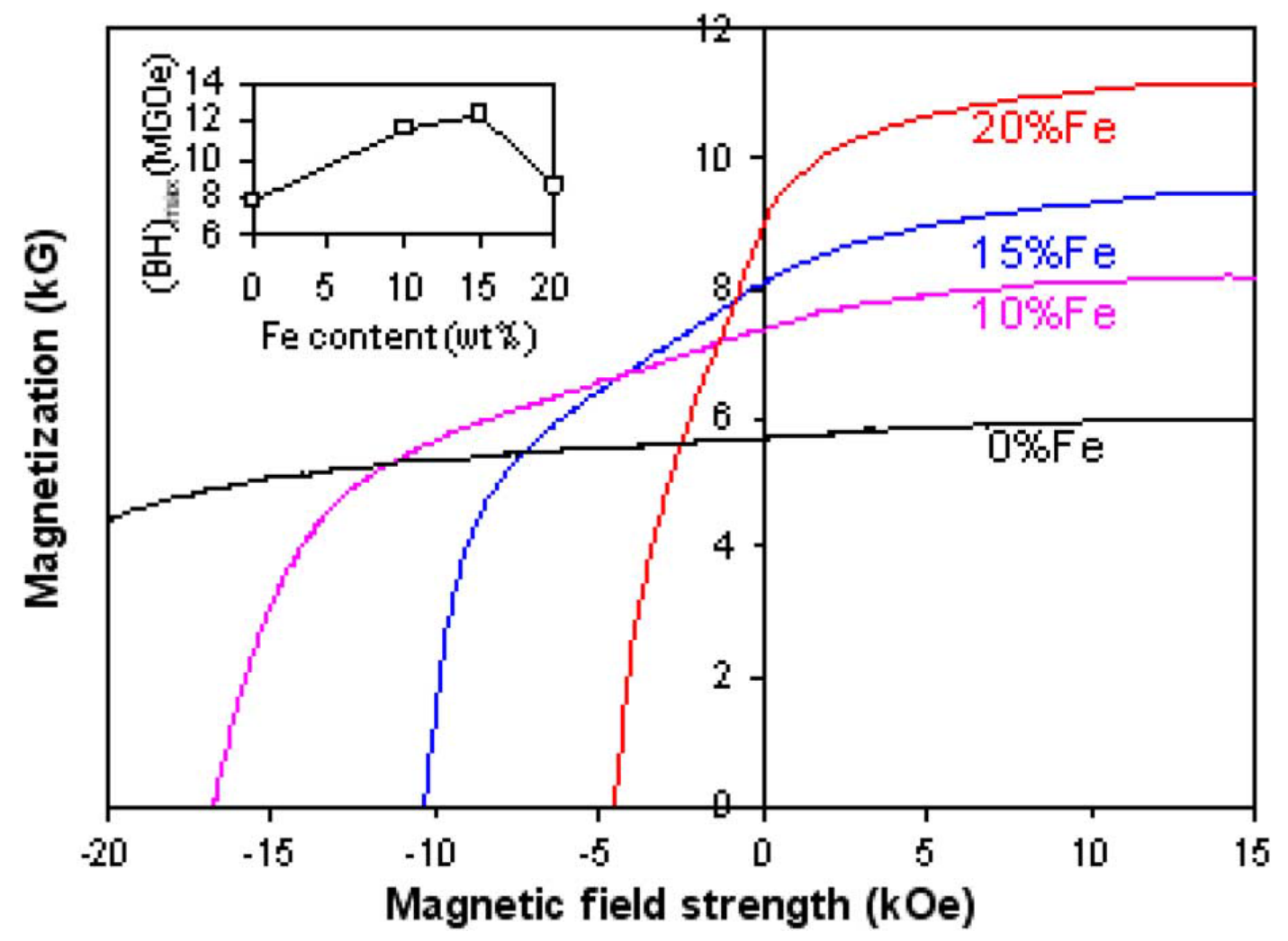

Figure 7. Demagnetization Curves of Bulk Sm-Co/a-Fe Magnets with Different Amounts of Fe Addition and Maximum Energy Product vs. Fe Content

The investigation showed that milling Fe and SmCo together resulted in a more uniformly distributed mixture of nanoscale soft phase particles, improved squareness of the demagnetization curves of bulk nanocomposite magnets, and higher maximum energy product as compared to blending Fe with SmCo (Figure 8). Milling time also directly affected demagnetization curves (Figure 9). 


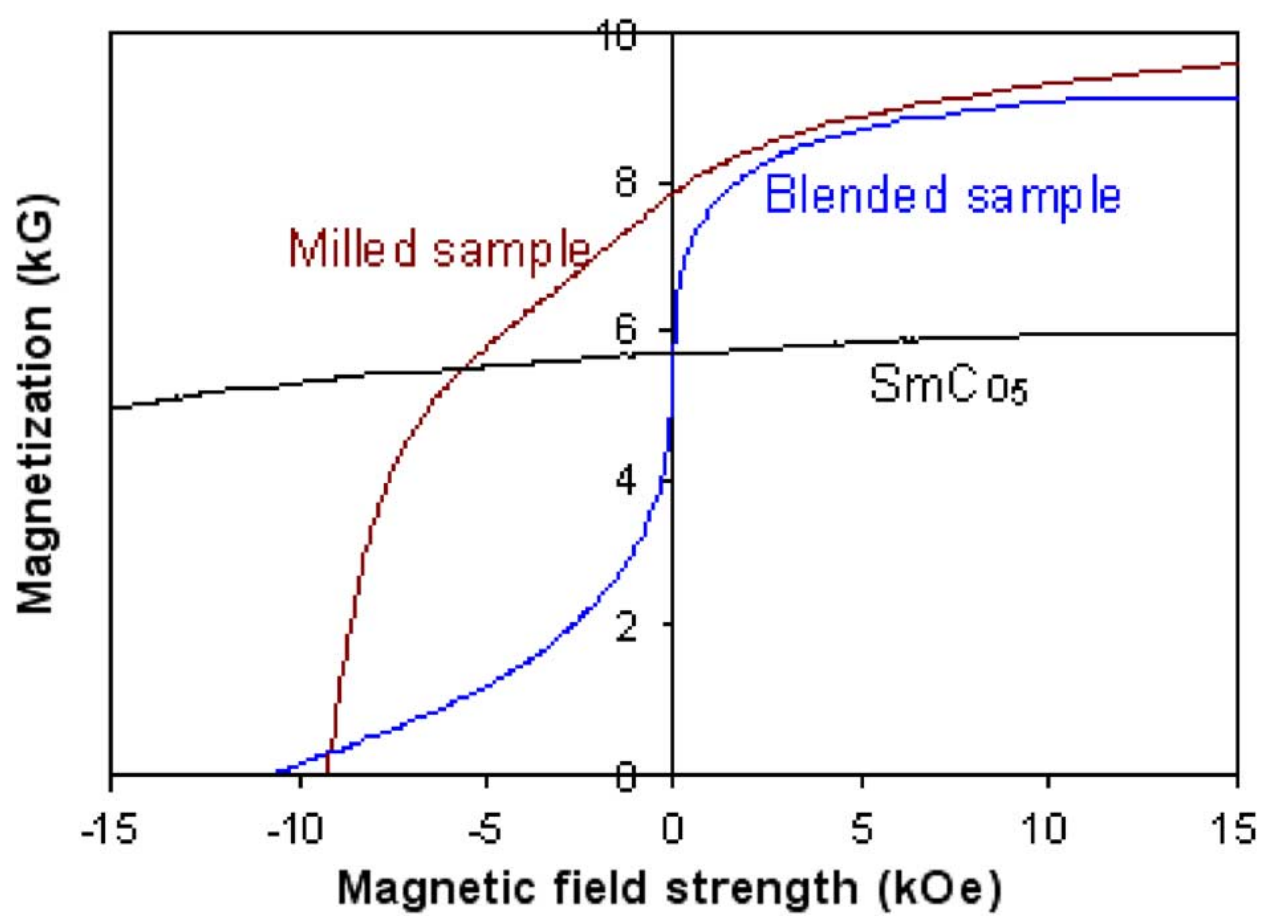

Figure 8. Demagnetization Curves for SmCo Magnet and Sm-Co-Fe Composite Magnets Prepared from Blended and Milled Powder

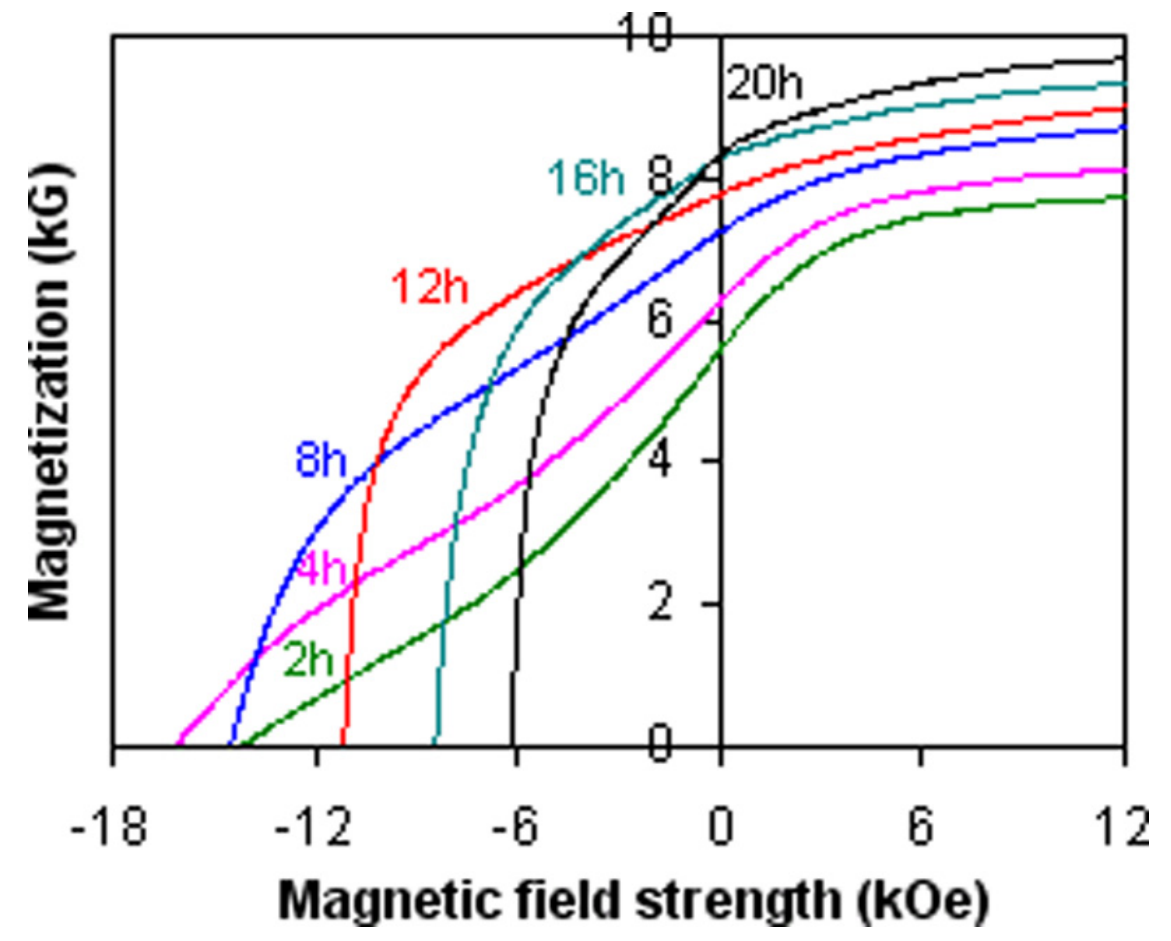

Figure 9. Demagnetization Curves of Bulk Sm-Co/a-(Fe,Co) Magnets as a Function of Milling Time

Substitution work also done with samarium cobalt based nanocomposites [14] [13]. Fluorine inclusion in alloys of $\mathrm{Sm}(\mathrm{Co}, \mathrm{Fe})_{z}$ with $\mathrm{z}>8.5$, for nanocomposites of the $2: 17$ hard phase and $\mathrm{Fe}-$ Co soft phase were investigated. Partial hysteresis loops are shown Figure 10. 


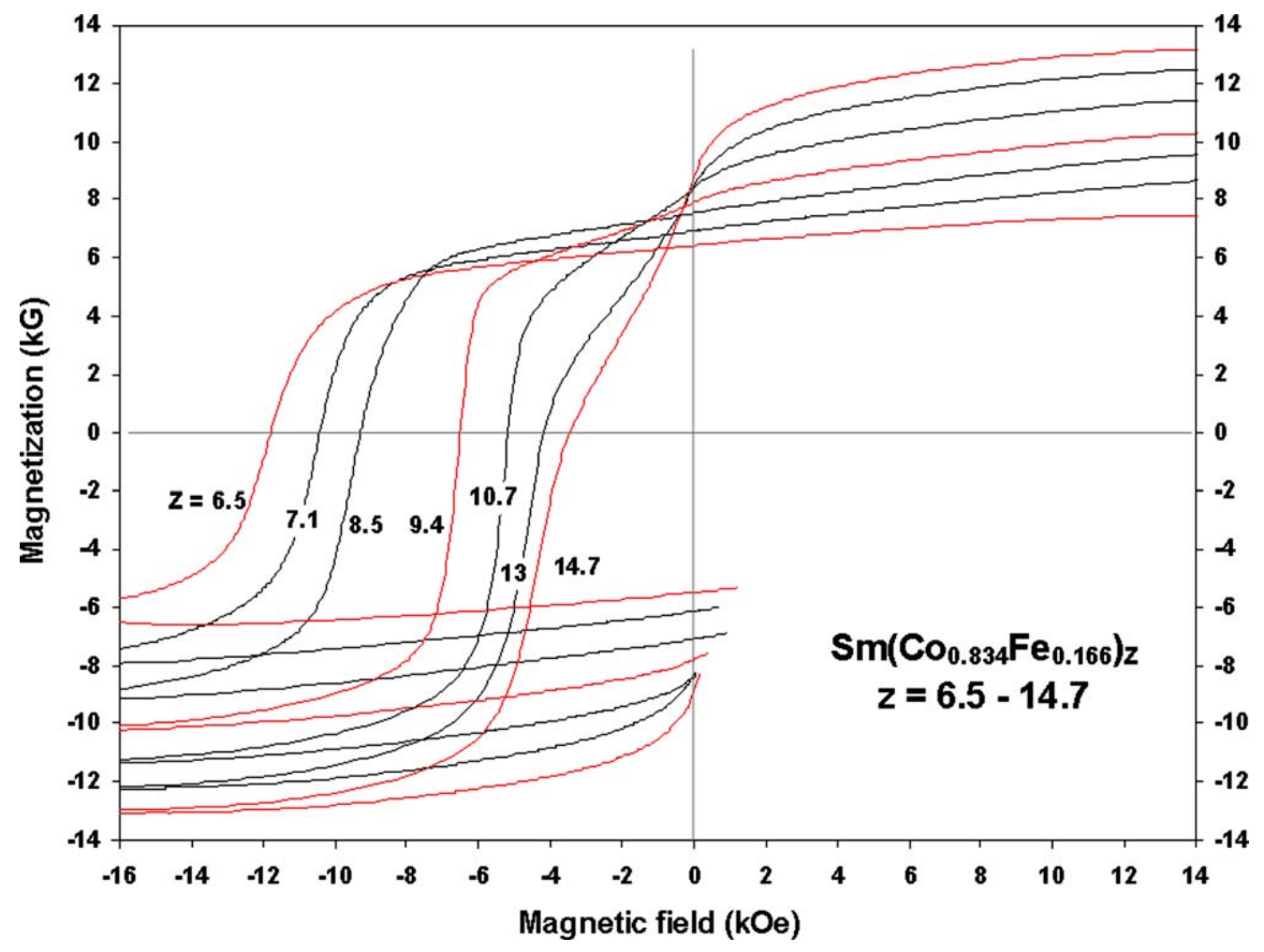

Figure 10. Partial Hysteresis Loops of $\mathrm{Sm}\left(\mathrm{Co}_{0.83} 4 \mathrm{Fe}_{0.166}\right)_{z}$ with $\mathrm{z}=6.5-14.7$

Figure 11 shows magnetic properties of the magnets as the soft phase increased in percent. Overall the inclusion of fluorine did not greatly improve magnetic performance as shown in Figure 12. 


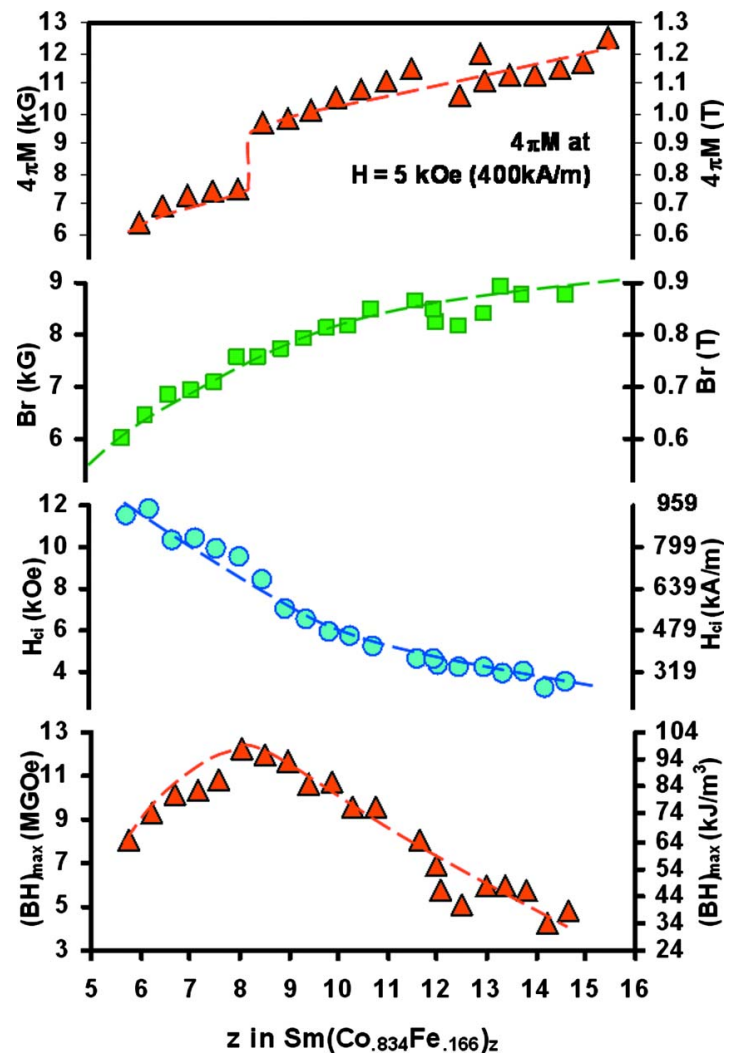

Figure 11. Magnetic Properties of $\mathrm{Sm}\left(\mathrm{Co}_{0.834} \mathrm{Fe}_{0.166}\right)_{z} \mathrm{vs}$. Effective $\mathrm{z}(28 \%$ soft phase for $\mathrm{z}=13$ and $35 \%$ soft phase for $z=14.7$ ) 

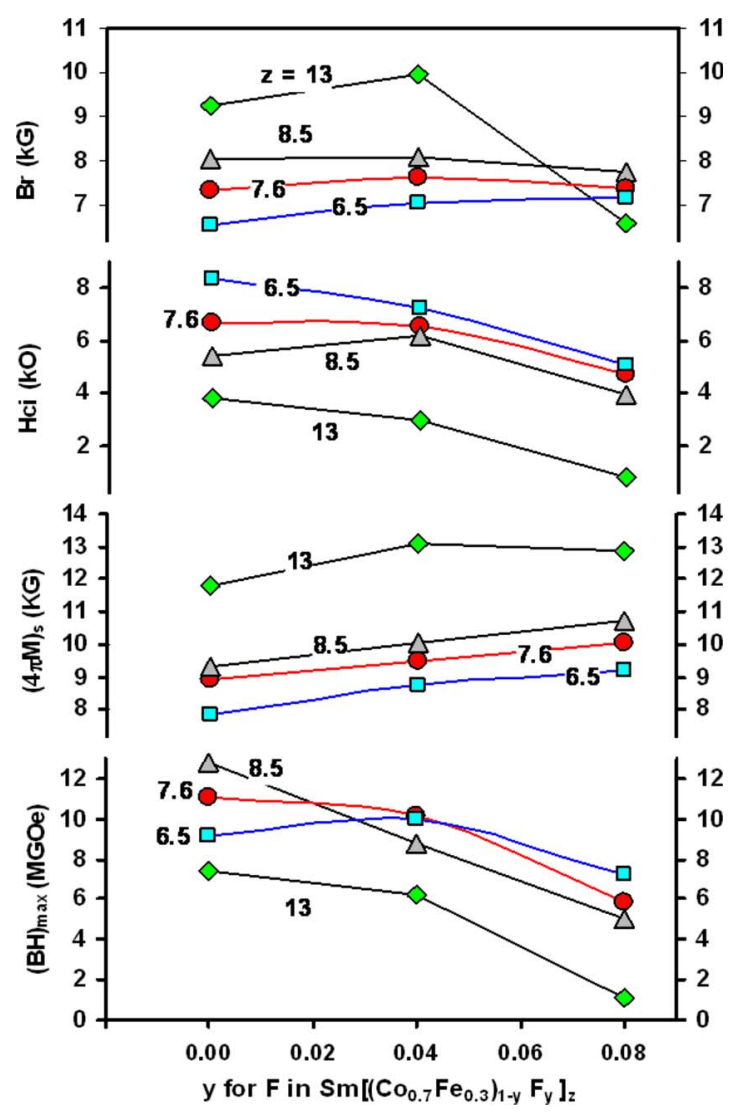

Figure 12. Effect of Fluorine Content on Magnetic Properties of $\mathrm{Sm}\left[\left(\mathrm{Co}_{0.7} \mathrm{Fe}_{0.3}\right)_{1-\mathrm{y}} \mathrm{Fy}\right]_{13}$ with $y=0,0.04$, and 0.08

Besides fluorine substitution, zirconium, niobium and copper substitutions were studied on samarium cobalt nanocomposite magnets [13]. Increasing zirconium content $\mathrm{x}$ from 0.02 to 0.05 led to significant refinement of the grain size in the melt-spun ribbons, from 80-150 to 20-50 $\mathrm{nm}$ as estimated by both XRD and SEM analyses. As a result of the formation of smaller grains, the coercivity and the maximum energy product were improved by $67 \%$ and $70 \%$ to $6.5 \mathrm{kOe}$ and 9.5 MGOe, respectively, as seen in Figure 13.
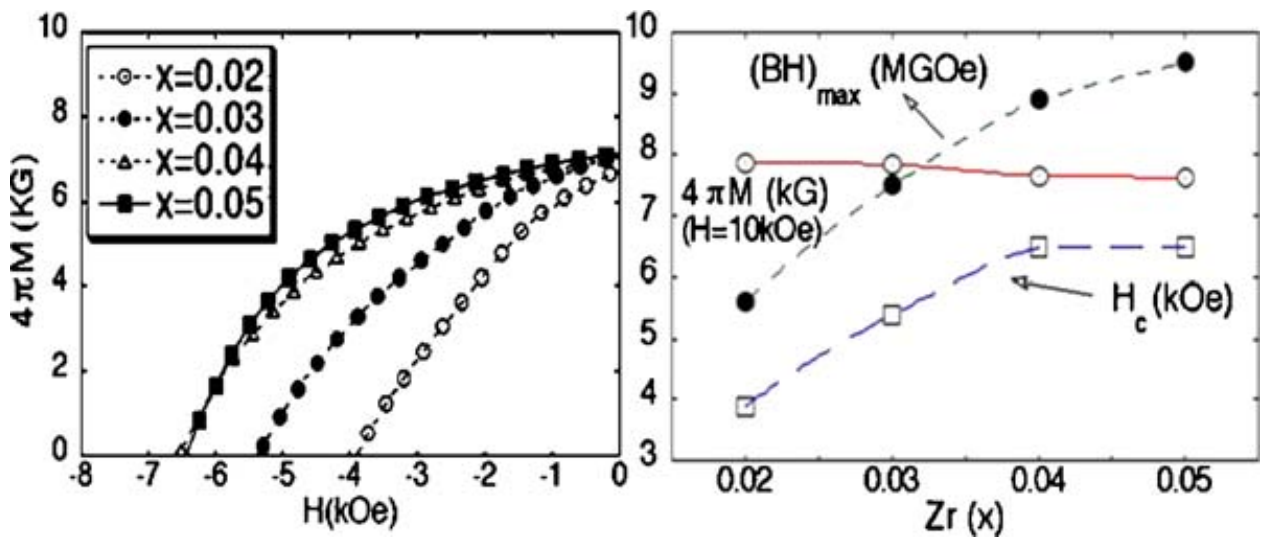

Figure 13. Demagnetization Curves and Magnetic Properties of Melt-spun $\mathrm{Sm}($ CobalFe0.3ZrxB0.04)10 Alloys with $\mathrm{x}=0.02$ to 0.05 
Copper substitution enhanced coercivity of the magnets. Table 2 shows the compositions for the copper substitution studies. This substitution increased the squareness, $\mathrm{H}_{\mathrm{k}} / \mathrm{H}_{\mathrm{c}}$ ratio, of the $\mathrm{BH}$ loops where $\mathrm{H}_{\mathrm{c}}$ is the coercivity and $\mathrm{H}_{\mathrm{k}}$ is the reversal field at $90 \%$ of the remanent magnetization (Figure 14).

Table 2. Compositions for Copper Substitution Studies

\begin{tabular}{|c|c|}
\hline No. & Composition \\
\hline 1 & $\mathrm{Sm}\left(\mathrm{Cobal} \mathrm{Fe}_{0.3} \mathrm{Zr}_{0.05} \mathrm{~B}_{0.04}\right) 10$ \\
\hline 2 & $\mathrm{Sm}\left(\mathrm{Cobal} \mathrm{Fe}_{0.3} \mathrm{Zr}_{0.05} \mathrm{~B}_{0.04} \mathrm{Cu}_{0.04}\right)_{10}$ \\
\hline 3 & $\mathrm{Sm}\left(\mathrm{Cobal} \mathrm{Fe}_{0.2 \mathrm{Z}} \mathrm{Zr}_{0.05} \mathrm{~B}_{0.04}\right) 8$ \\
\hline 4 & $\mathrm{Sm}\left(\mathrm{Cobal} \mathrm{Fe}_{0.2} \mathrm{Zr}_{0.05} \mathrm{~B}_{0.04} \mathrm{Cu}_{0.04}\right) 8$ \\
\hline
\end{tabular}
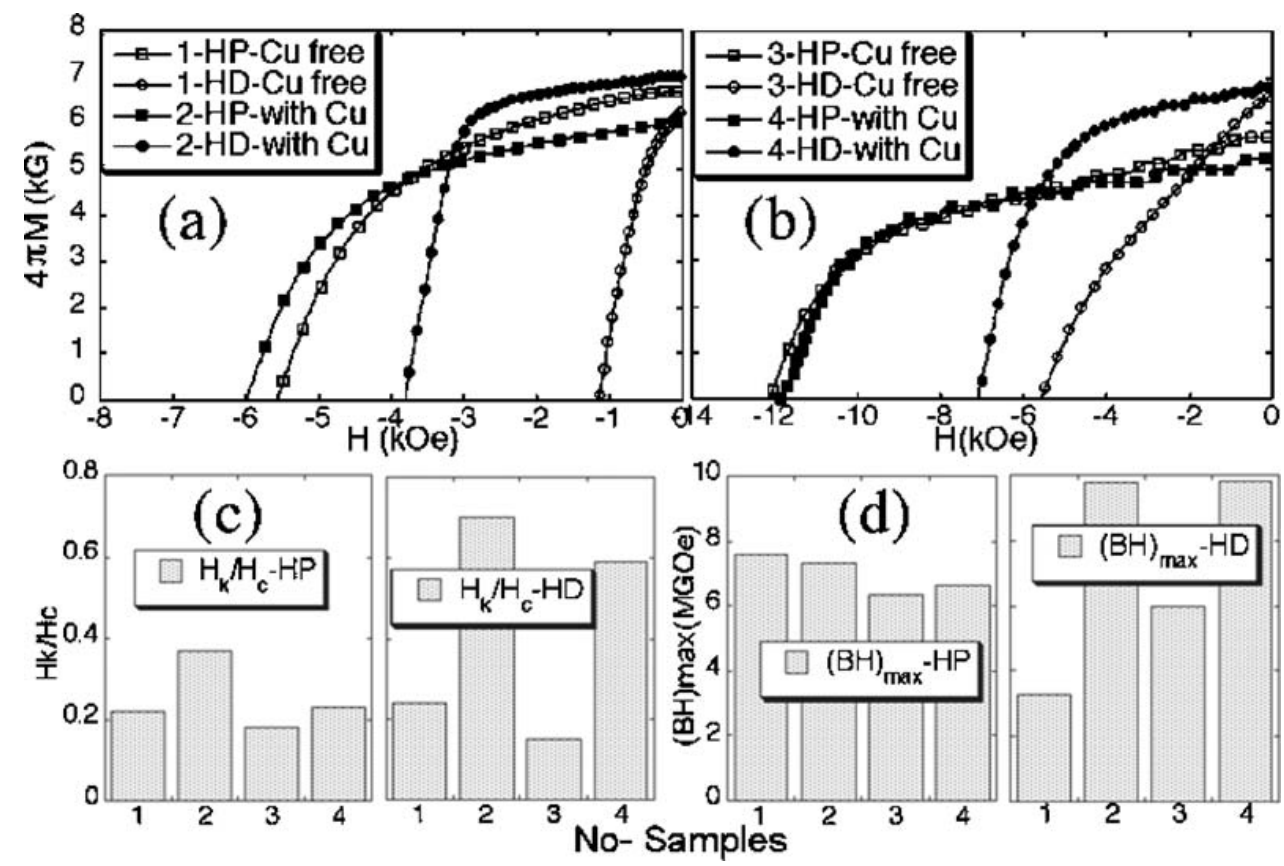

Figure 14. Demagnetization Curves (a) and (b), $\mathrm{H}_{\mathrm{k}} / \mathrm{H}_{\mathrm{c}}$ ratio (c), and $\mathrm{BH}_{\max }$ (d) of Bulk Magnets Nos. 1 to 4 after Hot Pressing (HP) and Hot Deformation (HD)

When niobium replaced copper in a composition the grain size further reduced but the squareness and maximum energy product were reduced.

The lanthanum cobalt work explored the making of a nanoncomposite of $\mathrm{LaCo}_{5} / \mathrm{LaCo}_{13}[15]$. For this nanocomposite work, the $\mathrm{LaCo}_{5}$ is the more coercive hard phase and the $\mathrm{LaCo}_{13}$ is the higher magnetization soft phase. As the soft fraction increased the magnet exhibited two-phase behavior, as seen in Figure 15. At 25 and $30 \% \mathrm{LaCo}_{7}$, the magnets had a smooth demagnetization curve and a coercivity of over $15 \mathrm{kOe}$. Figure 15 also shows a strong 
dependence on hot pressing temperature. This system shows promise as a permanent magnet system for high temperature applications.

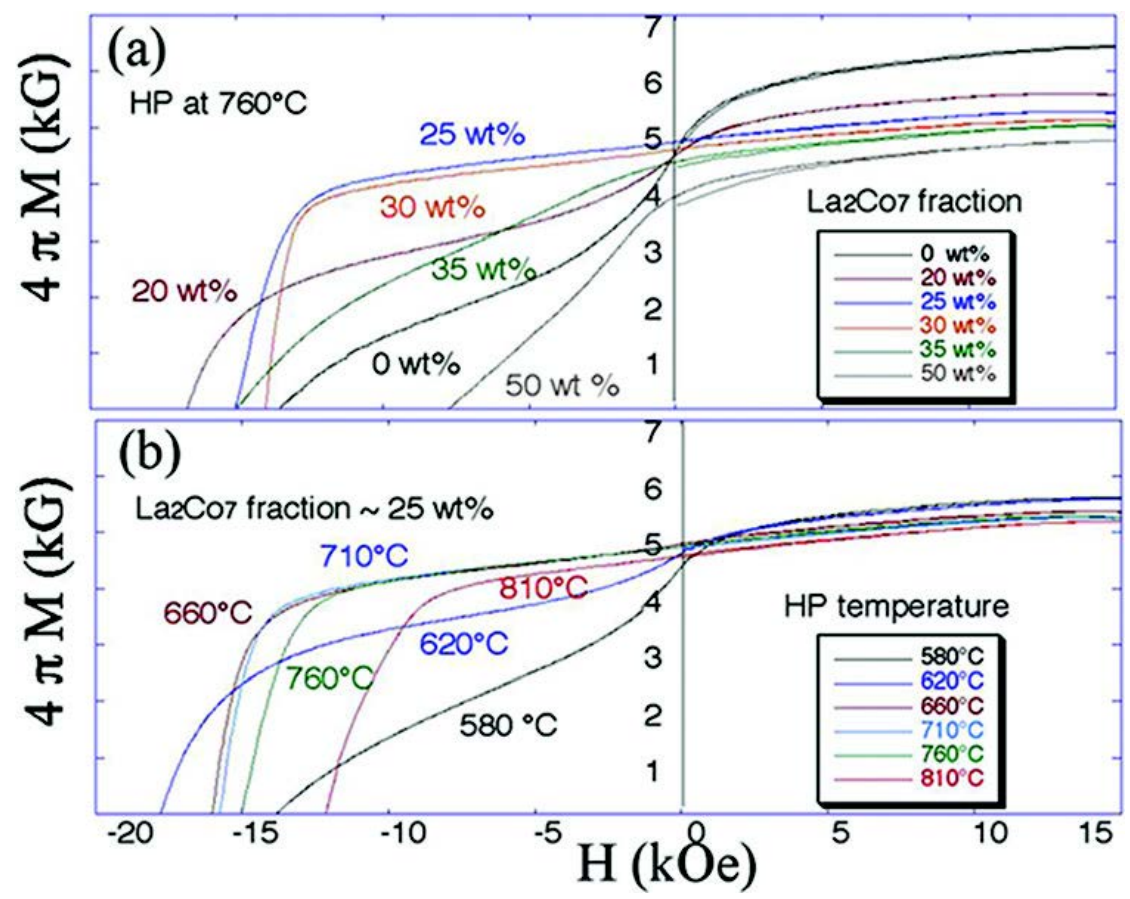

Figure 15. Demagnetization Curves of the Bulk La-Co Magnets

(Demagnetization curves are shown as (a) a function of $\mathrm{La}_{2} \mathrm{Co}_{7}$ weight fraction after hot pressing at 760 ${ }^{\circ} \mathrm{C}$ and (b) as a function of hot pressing temperature for 25 weight percent $\mathrm{La}_{2} \mathrm{Co}_{7}$.) 


\section{SOFT (TEMPORARY) MAGNETS}

\subsection{Iron Cobalt Research}

Iron cobalt alloys have the highest room temperature magnetization of any magnetic material. For this reason iron cobalt alloys are of interest to the aerospace industry where volume and weight are important. This work unit included research on iron cobalt alloys [16] [17]. The powder metallurgy processing of a gas atomized $\mathrm{FeCoNbV}$ alloy through hot isostatic pressing was studied. After hot isostatic pressing, the compacts were subjected to an ordering or disordering heat treatment in which the samples were heated up to $730{ }^{\circ} \mathrm{C}$ followed by a slow furnace cooling (ordered) or water quenching (disordered). Ball milling of the powder prior to hot isostatic pressing improved the yield strength by about $35 \%$. Figure 16 shows the results for the four different processing conditions.

Table 3 shows the yield strength of two compositions as a function of oxidation time and temperature. For all samples the yield strength initially dropped with oxidation time and then the yield strength increased although the niobium containing samples did not surpass initial yield strength. The strengthening with aging time seems to be due precipitation reactions in the samples.

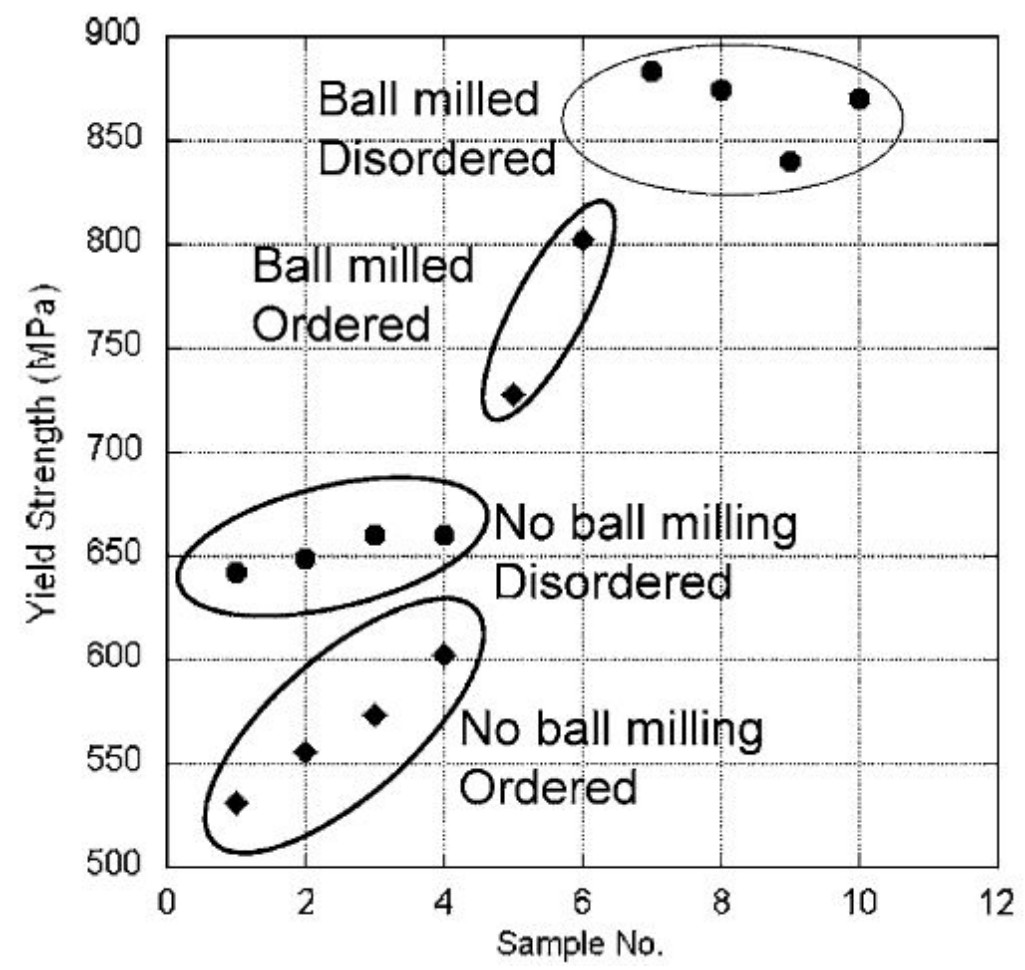

Figure 16. Yield Strengths of $750^{\circ} \mathrm{C}$ Hot Isostatic Pressed Materials for Given Annealing and Ball Milling Conditions 
Table 3. Yield Strength Values of FeCoV and FeCoVNb Alloys Measured at Room Temperature and $482{ }^{\circ} \mathrm{C}$ as a Function of Oxidation Time

\begin{tabular}{|c|c|c|c|c|}
\hline & \multicolumn{2}{|l|}{ FeCo-2V } & \multicolumn{2}{|c|}{$\mathrm{FeCo} 2 \mathrm{~V}-0.3 \mathrm{Nb}$} \\
\hline & $\begin{array}{l}\text { Yield } \\
\text { Strength }\end{array}$ & $\begin{array}{l}\text { Yield } \\
\text { Strength }\end{array}$ & $\begin{array}{l}\text { Yield } \\
\text { Strength }\end{array}$ & $\begin{array}{l}\text { Yield } \\
\text { Strength }\end{array}$ \\
\hline Time & Room T & $482 \mathrm{C}$ & Room T & $482 \mathrm{C}$ \\
\hline (hours) & (MPa) & $(\mathrm{MPa})$ & (MPa) & (MPa) \\
\hline 0 & 417 & 410 & 545 & 484 \\
\hline 100 & 403 & 363 & 489 & 450 \\
\hline 1000 & 426 & 401 & 479 & 416 \\
\hline 2000 & 427 & 351 & 374 & 352 \\
\hline 5000 & 524 & 460 & 390 & 379 \\
\hline
\end{tabular}

\subsection{Tape Core Research}

Soft magnetic research includes both research into tape core materials and research involving inductor applications. The tape core research involves both amorphous or nanocrystalline materials [18] [19]. This work studied the properties and nanocrystallization characteristics of HITPERM based $\mathrm{Fe}_{68.8} \mathrm{Co}_{17.2} \mathrm{Hf}_{7} \mathrm{Cu}_{1} \mathrm{~B}_{6}$ and $\mathrm{Fe}_{69.6} \mathrm{Co}_{17.4} \mathrm{Hf}_{7} \mathrm{~B}_{6}$ alloys. The alloys only differed in containing copper. These alloys were prepared by arc melting and then melt spinning at a wheel speed of $35 \mathrm{~m} / \mathrm{s}$. The presence of copper had no effect on the grain size of the alloys. Their respective magnetization curves as a function of increasing temperature are shown in Figure17.

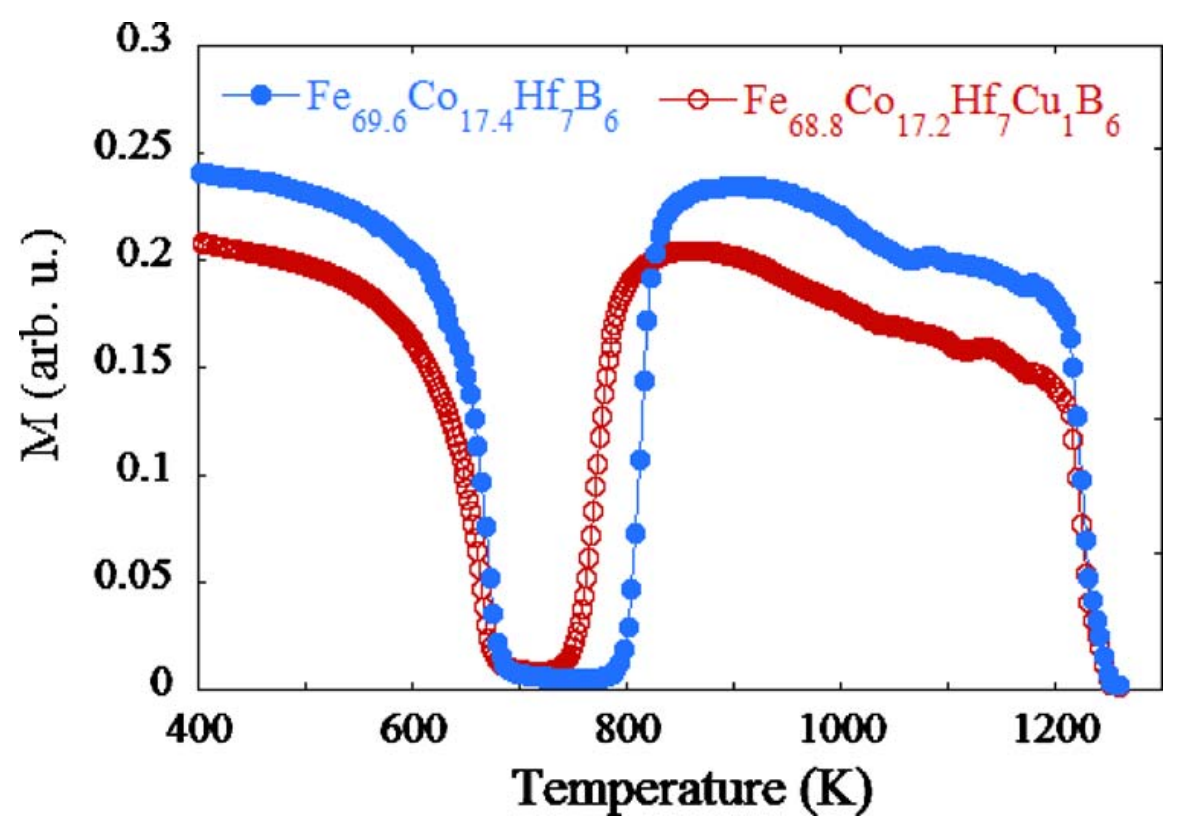

Figure 17. Thermomagnetic $M(T)$ Plots of $\mathrm{Fe}_{68.8} \mathrm{Co}_{17.2} \mathrm{Hf}_{7} \mathrm{Cu}_{1} \mathrm{~B}_{6}$ and $\mathrm{Fe}_{69.6} \mathrm{Co}_{17.4} \mathrm{Hf}_{7} \mathrm{~B}_{6}$ Alloys Measured under an Applied Field of $1 \mathrm{kOe}$

These samples first go through their amorphous Curie temperature which drops the magnetization and then after crystallization a second drop occurs due to a phase change from bcc 
to fcc. The crystallization temperature of the copper containing alloy was higher at $808 \mathrm{~K}$ then the copper free alloy at $770 \mathrm{~K}$. Overall, the addition of copper has no effect on final grain size, but it increases coercivity and lowers saturation magnetization and permeability.

In another study nanocrystalline iron cobalt based alloys with $\mathrm{Hf}$ or Ta or both were investigated for high frequency applications. Magnetization and calorimetry plots are shown in Figure 18. Amorphous alloys of $\left(\mathrm{Fe}_{81} \mathrm{Co}_{19}\right)_{84} \mathrm{M}_{9} \mathrm{~B}_{7}$ where $\mathrm{M}=(\mathrm{Hf}, \mathrm{Ta}$, or $\mathrm{HfTa})$ were prepared by meltspinning. The alloys were then annealed for increasing times at their respective crystallization temperatures. Overall, the nanocrystalline alloys had coercivities less than $0.4 \mathrm{Oe}$ and saturation inductions greater than 1Tesla. The electrical resistivities of the amorphous ribbons were all similar with values of $\sim 180 \mathrm{Ohm}-\mathrm{cm}$. After annealing at the crystallization temperature, the $\mathrm{M}=\mathrm{Ta}$ alloy had the largest resistivity of $140 \mathrm{Ohm}-\mathrm{cm}$. The Ta alloy also had the best high frequency properties, with an initial permeability of 822 at $1 \mathrm{MHz}$. Figure 19 shows the complex permeability of the Ta alloy as a function of frequency.

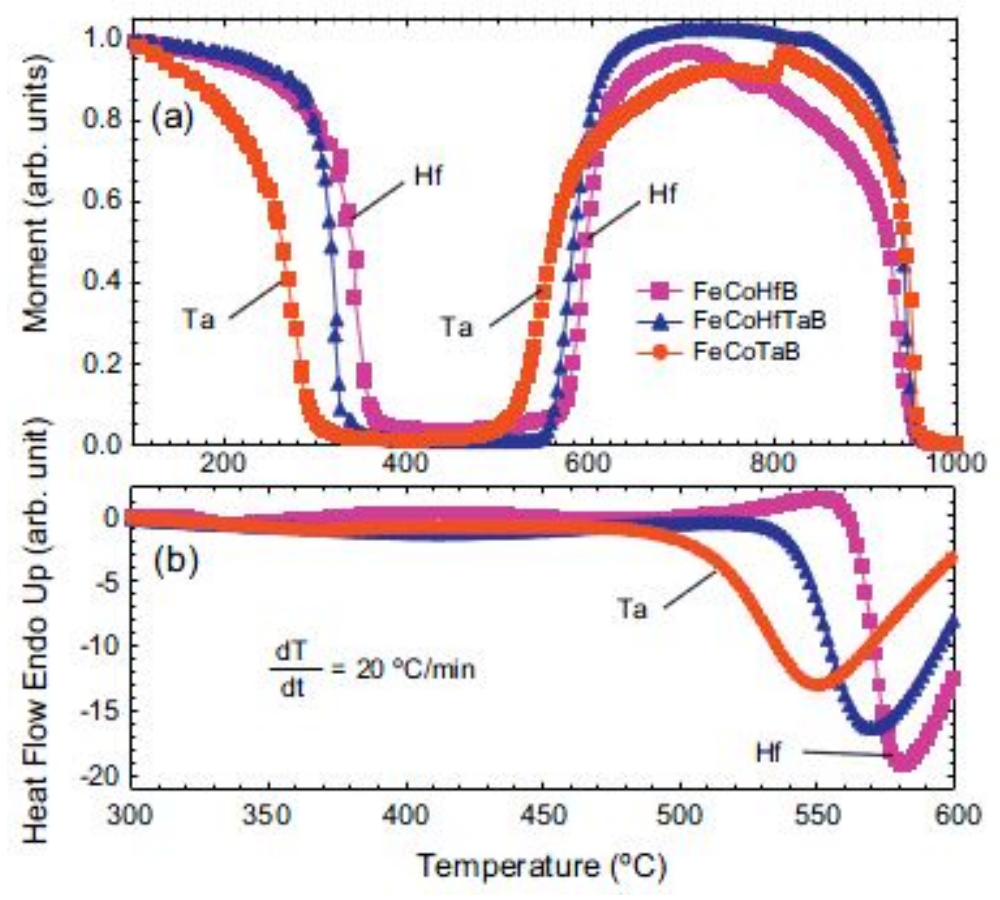

Figure 18. Magnetization as a Function of Temperature from Vibrating Sample Magnetometry and Results from Differential Scanning Calorimetry 


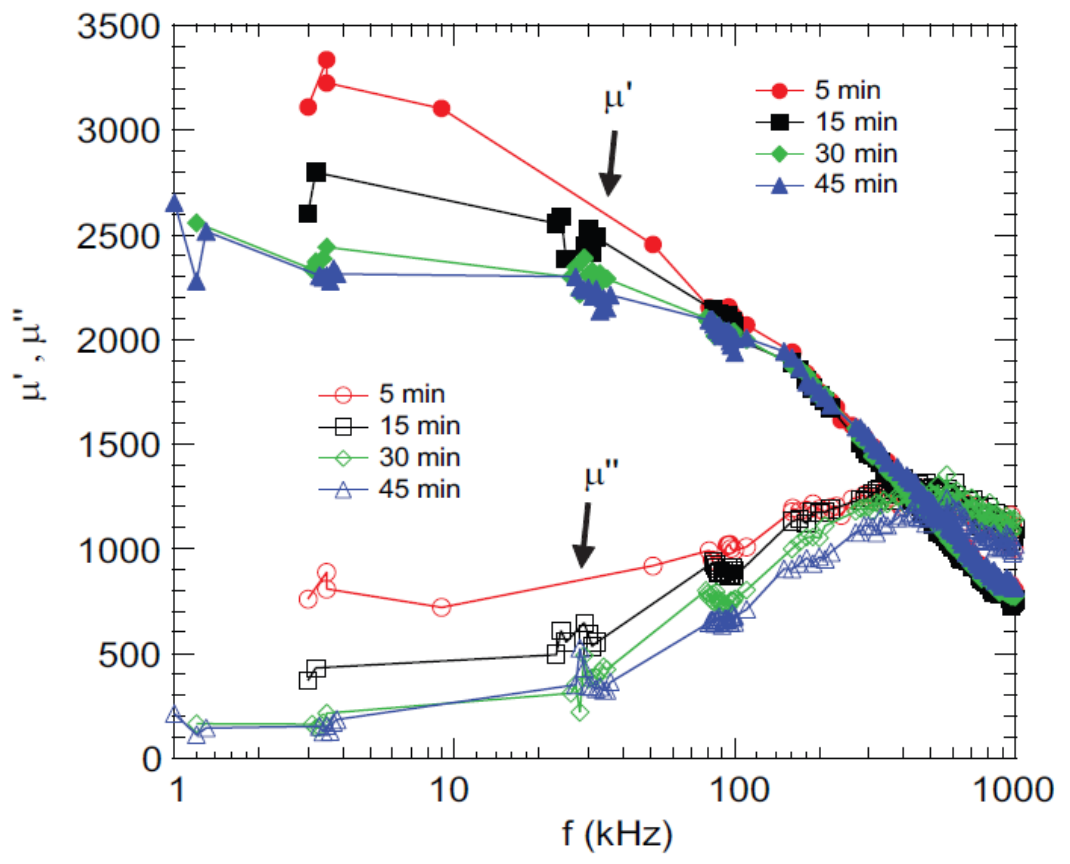

Figure 19. Initial AC Permeabilities as a Function of Frequency for the FeCoTaB Sample Annealed at $\mathrm{Tx} 1=551.8 \mathrm{C}$ for increasing anneal times

\subsection{Basic Science of Soft Magnetic Materials}

The basic science of soft magnetic materials included research on phonon density of states of magnetic alloys, high-entropy magnetic alloys and magnetocaloric alloys. Most of these studies involved measurements at Department of Energy National Laboratories. X-ray scattering measurements were performed at Argonne National Laboratory and neutron scattering measurements were performed at Oak Ridge National Laboratory.

The high-entropy alloys studies all involved alloys containing iron and usually nickel, chromium and cobalt [20] [21] [22]. These materials were studied as candidates for magnetic or magnetocaloric use. High-entropy alloys have nearly equal atomic fractions of each of their component elements. These materials have been studied for their high mechanical and chemical properties such in hardness, wear resistance, and corrosion resistance. Long-range chemical ordering, magnetic and vibrational properties, and magnetic entropy were investigated on these alloys. Figure 20 shows a vibrational density of state result for an equimolar FeCoCrNi alloy. This fcc FeCoCrNi alloy was given a heat treatment at $480{ }^{\circ} \mathrm{C}$ for two weeks and then slow cooled to room temperture. Comparing the phonon density of states from neutron scattering measurements to a study on the Fe-atom vibrational modes suggests that there is no evidence of long-range chemical ordering. 


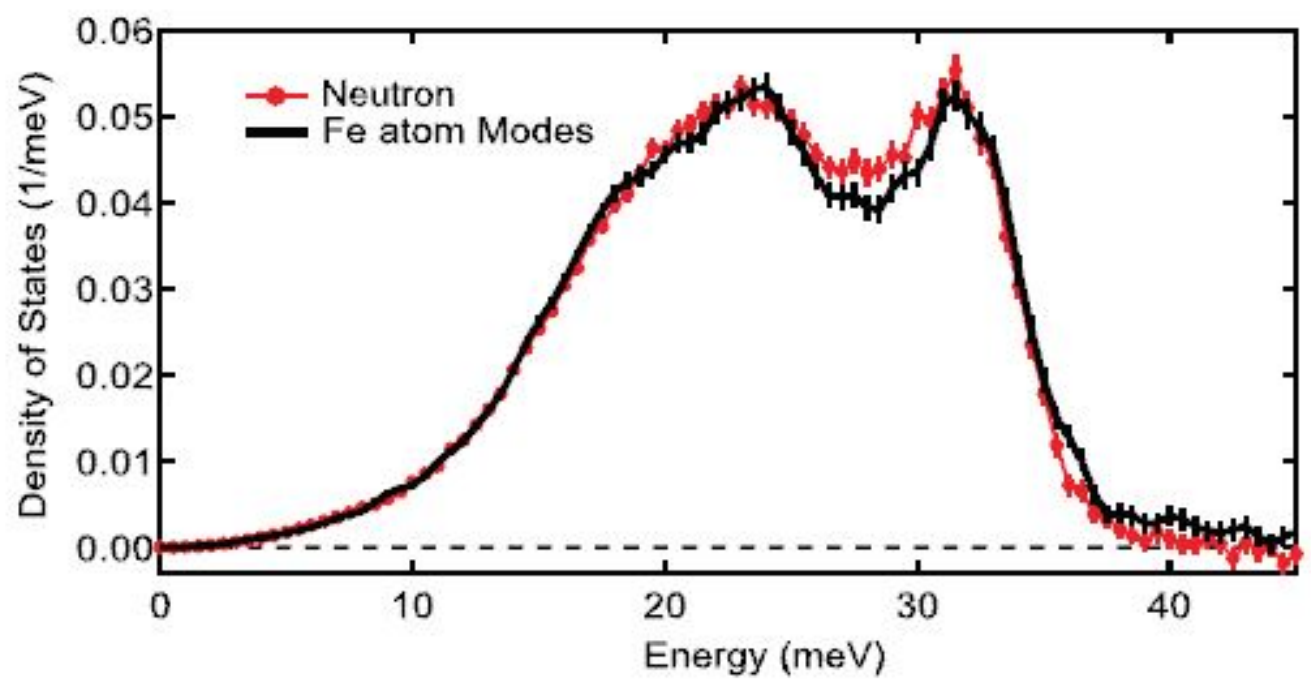

Figure 20. Vibrational Density of States for FeCoCrNi from Inelastic Scattering of Neutrons and X-rays

Binary alloys such as Fe-Co, Ni-Fe and Fe-V were also studied [23] [24] [25] [26]. The Fe-Co system is magnetically important due to its high Curie temperature, high magnetization and high permeability. These alloys may be disordered or ordered. Ordered Fe-Co alloys tend to be brittle and are less useful for engineering applications. The disordered phase can be obtained by quenching from the high temperature disordered phase. Figure 21 shows the small but observable change of phonon energy due to order. The ordered alloy has on average stiffer bonds due to more unlike bonds compared to the disordered alloy.

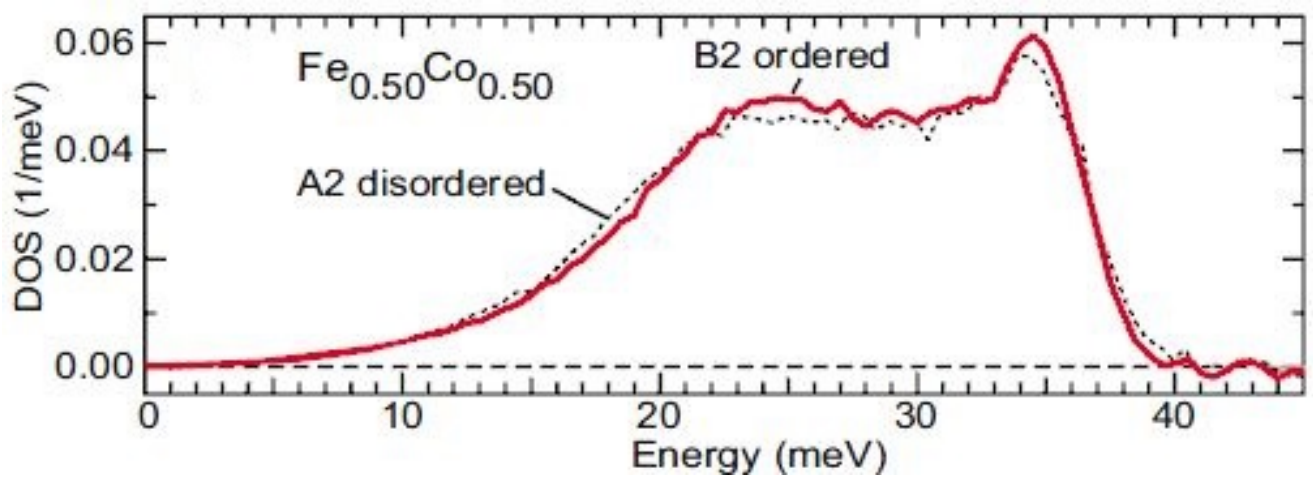

Figure 21. Phonon Density of State Curves for Disordered and Ordered $\mathrm{Fe}_{0.50} \mathrm{Co}_{0.50}$ Alloys

The bec phase of the iron-vanadium alloy system spans the full composition range. Phonon density of states as composition varies is shown in Figure 22. Changes in magnetic properties with composition make these alloys interesting to study the effects of magnetism on phonon thermodynamics. 


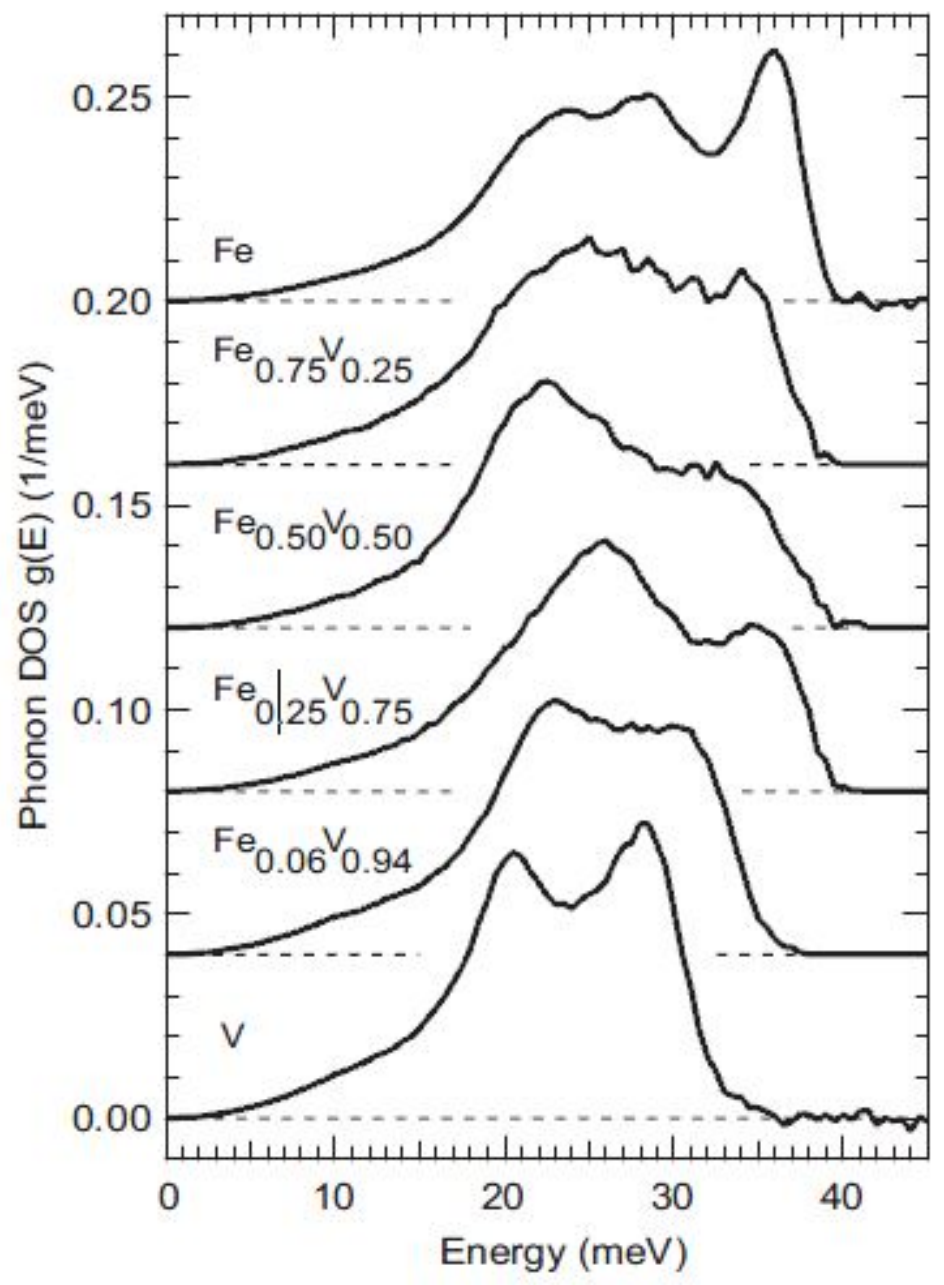

Figure 22. Phonon Density of State Curves for Fe, V and Fe-V Alloys

(The alloys are at $300 \mathrm{~K}$, corrected for neutron weighting and with curves offset by integer multiples of $0.04 \mathrm{meV}^{-1}$.) 


\section{APPLICATIONS AND MODELING}

\subsection{Permanent Magnet Solenoids}

One major application addressed in this research effort was the modeling and building of a large bore permanent magnet solenoid [27] [28]. The center magnetic field needed to be very uniform for this application. Figure 23 shows the overall design with a section cut out for clarity.

Modeling was performed using ANSYS Maxwell. One caveat in particular for the modeling of the field for the solenoid was the role of surrounding air region or padding space (Figure 24). If the air region was too small the field accuracy was increasingly incorrect as shown in Figure 25. Figure 26 shows the uniformity of the magnetic field at the center axial position and at a position $50 \mathrm{~mm}$ from center. The modeled versus measured magnetic field agree to within $5 \%$. The completed magnet assembly is shown in Figure 27.
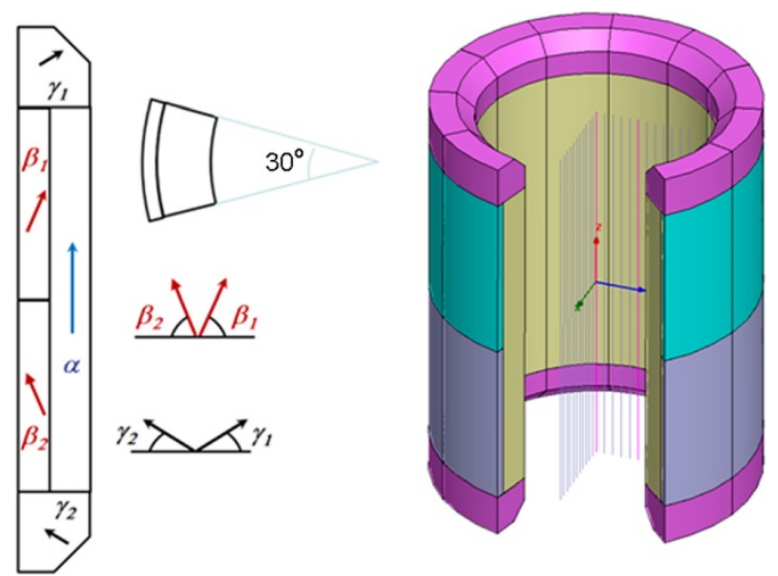

Figure 23. Design of a Permanent Magnet Solenoid

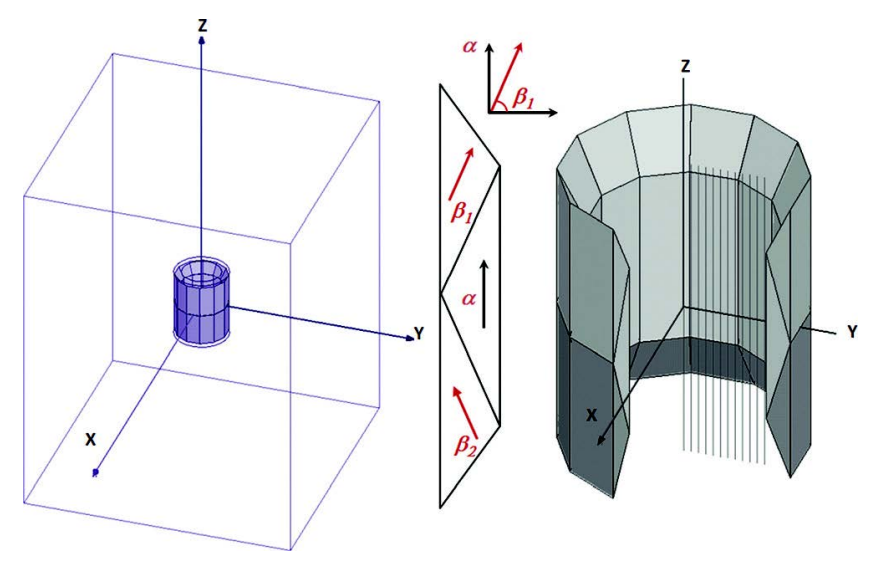

Figure 24. Solenoid Model

(Left: the solenoid with 200\% padding space. Center: cross section showing the magnetic vector directions. Right: cut-off view of the permanent magnet solenoid.) 


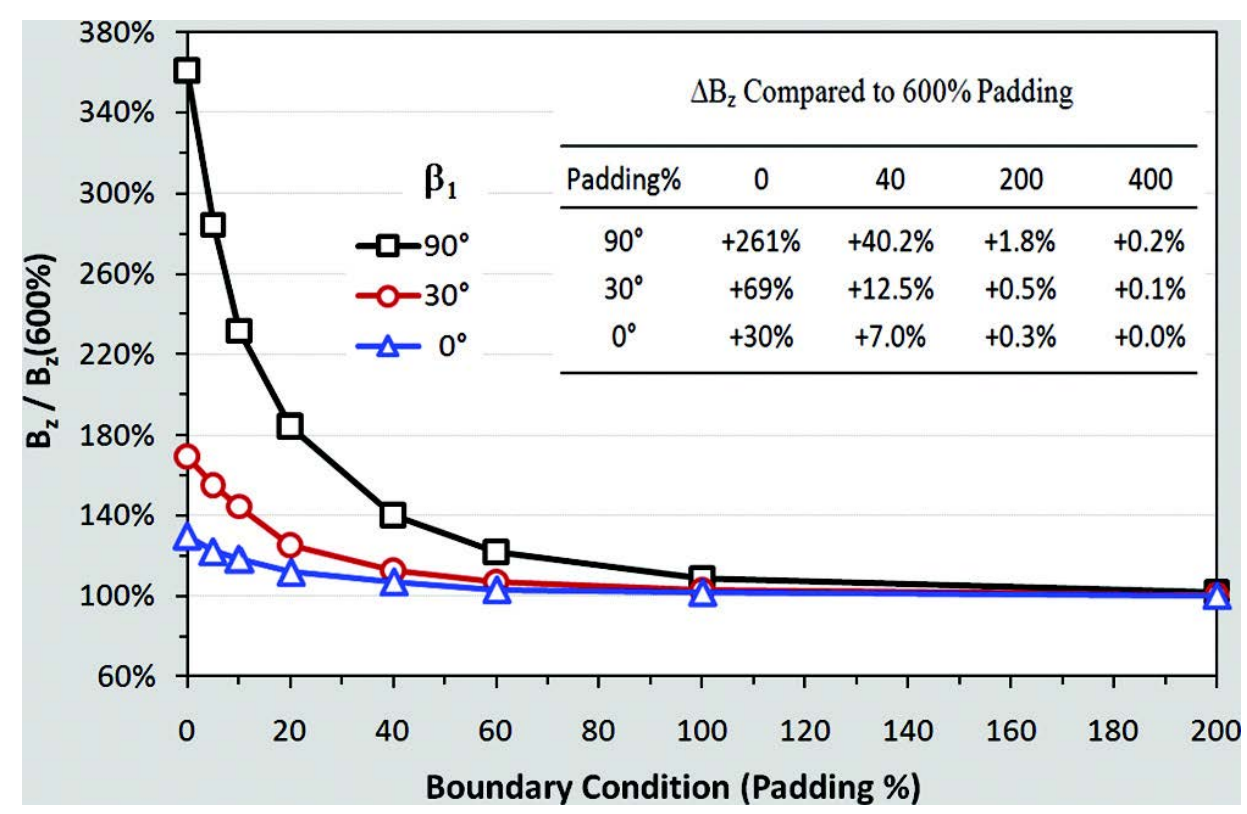

Figure 25. Ratio of the $B z$ over the $B z(600 \%)$ vs. Padding $\%$ for the Three Solenoids $\left(\beta_{1}=\right.$ $90^{\circ}, 30^{\circ}$, and $0^{\circ}$ )

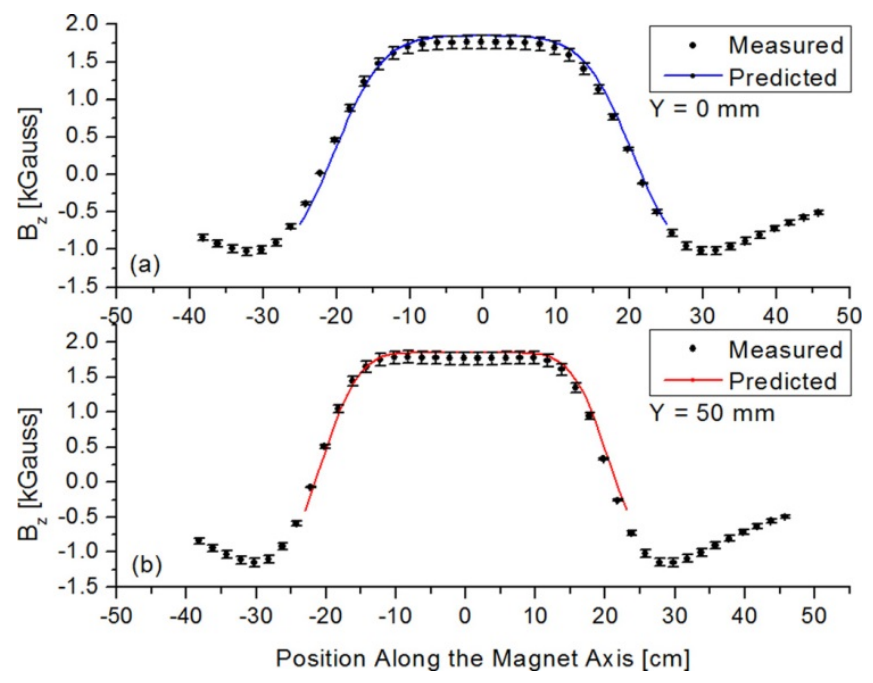

Figure 26. Magnetic Field Uniformity 


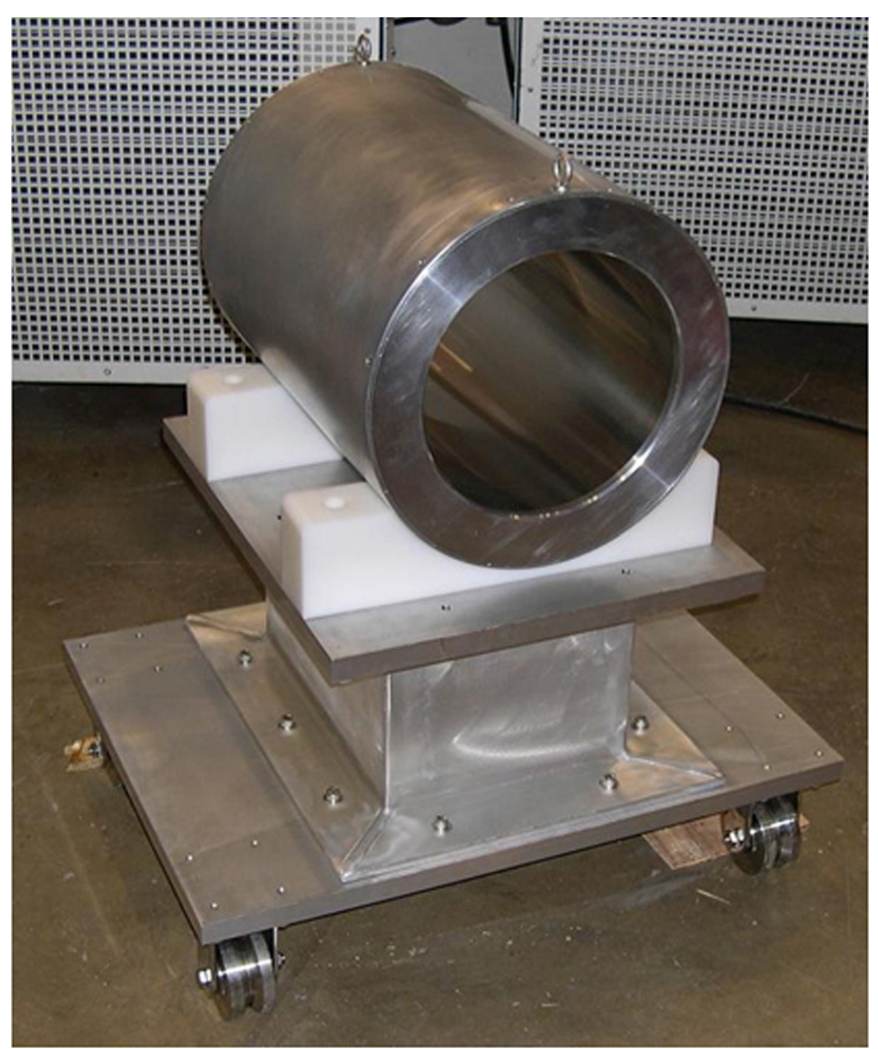

Figure 27. Magnet Assembly with an Inner Bore of $27 \mathrm{~cm}$ and Support Stand

\subsection{Cores for Converters}

Cores were investigated for use in DC-DC boost converters. This work was done in collaboration with AFRL/RQQE. In the first study three types of coupled inductors were investigated for performance [29]. The test circuit for this work is shown in Figure 28. Three types of ferrite cores were made (Figure 29). Efficiency data of the cores is given in Table 4. Pickup coil locations are shown in Figure 30. The square core with the forty-five degree gaps had the best performance as given in Table 5. The field distributions for the square $45^{\circ}$ gap core inductor were also more uniform throughout the core than the other two inductor types (Table 5).

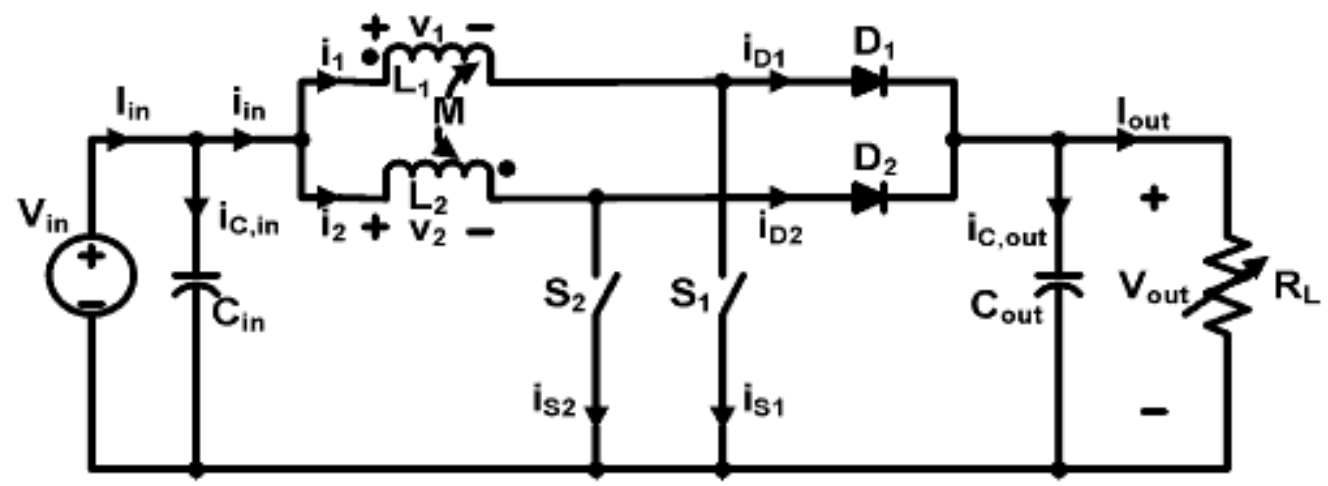

Figure 28. Circuit of an Interleaved Boost dc-dc Converter 


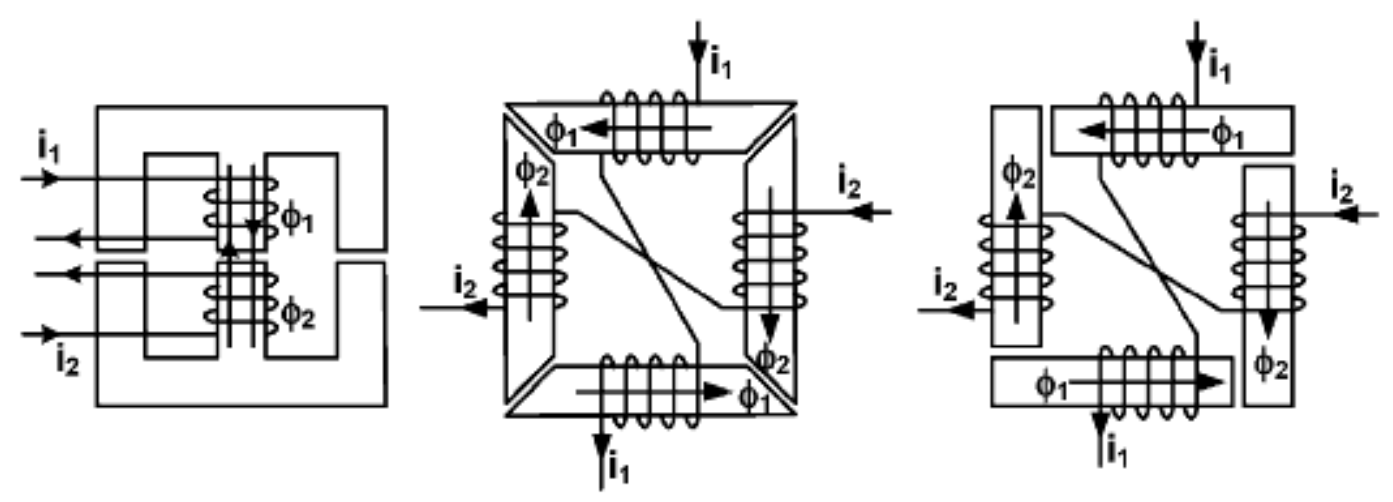

Figure 29. Winding Configuration of the Coupled Inductors

( $L$ to $R$ : E-E core, square 45 gap core, and square 90 gap core.)

Table 4. Boost Converter Efficiency Data

\begin{tabular}{|l|l|l|l|l|l|c|}
\hline $\begin{array}{l}\text { Inductor } \\
\text { type }\end{array}$ & $\begin{array}{l}\text { Vin } \\
(\mathrm{V})\end{array}$ & $\begin{array}{l}\text { Iin } \\
(\mathrm{A})\end{array}$ & $\begin{array}{l}\text { Vout } \\
(\mathrm{V})\end{array}$ & $\begin{array}{l}\text { Pout } \\
(\mathrm{A})\end{array}$ & $\begin{array}{l}\text { Pout } \\
(\mathrm{W})\end{array}$ & $\begin{array}{l}\text { Converter } \\
\text { efficiency } \\
(\%)\end{array}$ \\
\hline E-E core & 60.0 & 27.57 & 158.7 & 9.69 & 1538 & 93.0 \\
\hline Square $90^{\circ}$ gap & 60.0 & 27.44 & 158.8 & 9.64 & 1531 & 93.0 \\
\hline Square $45^{\circ}$ gap & 60.0 & 27.20 & 158.8 & 9.79 & 1555 & 95.2 \\
\hline
\end{tabular}
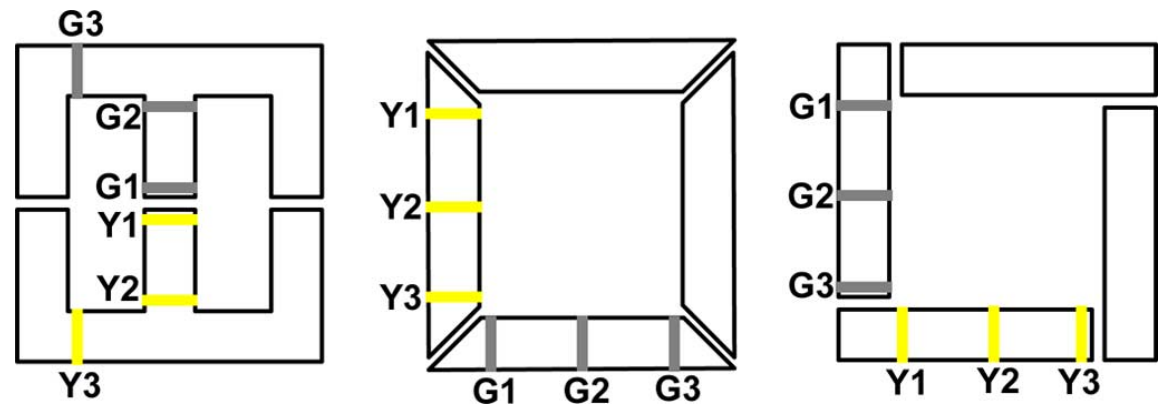

Figure 30. Pickup Coil Location for the Coupled Inductors 
Table 5. Calculated and Simulated AC Flux

\begin{tabular}{|c|c|c|c|c|c|c|}
\hline $\begin{array}{c}\text { Inductor } \\
\text { Type }\end{array}$ & $\begin{array}{c}\mathrm{Y} 1 \\
(\mu \mathrm{Wb})\end{array}$ & $\begin{array}{c}\mathrm{Y} 2 \\
(\mu \mathrm{Wb})\end{array}$ & $\begin{array}{c}\mathrm{Y} 3 \\
(\mu \mathrm{Wb})\end{array}$ & $\begin{array}{c}\mathrm{G} 1 \\
(\mu \mathrm{Wb})\end{array}$ & $\begin{array}{c}\mathrm{G} 2 \\
(\mu \mathrm{Wb})\end{array}$ & $\begin{array}{c}\mathrm{G} 3 \\
(\mu \mathrm{Wb})\end{array}$ \\
\hline E-E core & 1.76 & 2.07 & 0.84 & 1.45 & 1.58 & 0.69 \\
\hline $\begin{array}{c}\text { Simulation } \\
(\mathrm{E}-\mathrm{E})\end{array}$ & 1.36 & 1.85 & 0.90 & 1.24 & 1.32 & 0.64 \\
\hline $\begin{array}{c}\text { Square } \\
\left(45^{\circ} \text { gap) }\right.\end{array}$ & 1.65 & 1.96 & 1.67 & 1.30 & 1.42 & 1.28 \\
\hline $\begin{array}{c}\text { Simulation } \\
\left(45^{\circ} \text { gap) }\right.\end{array}$ & 1.84 & 2.10 & 1.83 & 1.75 & 1.85 & 1.75 \\
\hline $\begin{array}{c}\text { Square } \\
\left(90^{\circ} \text { gap) }\right.\end{array}$ & 1.58 & 1.65 & 1.28 & 1.20 & 1.23 & 1.00 \\
\hline $\begin{array}{c}\text { Simulation } \\
\left(90^{\circ} \text { gap) }\right.\end{array}$ & 1.80 & 2.10 & 1.86 & 1.69 & 1.85 & 1.75 \\
\hline
\end{tabular}

Note: For 1 amp through the coil on which the pickup coils are placed.

In the second study loss mechanisms were studied with a DC bias [30]. Inductors or transformer cores in electronic systems are often subjected to DC bias-flux conditions. These DC bias conditions can result in distorted hysteresis loops and increased core losses. The wound core for this study is shown in Figure 31. The test circuit is shown in Figure 32. This study found that Steinmetz equation for loss underestimated losses under DC bias Figure 33. The Steinmetz equation is

$$
\mathrm{P}=\mathrm{Af}^{\alpha} \mathrm{B}^{\beta^{\prime}}
$$

where $\mathrm{P}$ is power los $(\mathrm{W} / \mathrm{kg}), \mathrm{A}$ is the fitting coefficient, $\mathrm{f}$ is the frequency $(\mathrm{kHz})$ and $\mathrm{B}$ is the flux density (Tesla) and $\alpha$ and $\beta$ are fitted exponential factors. A pre-magnetization field increases core losses as shown in Figure 34. These losses are a design consideration especially for cores operated at greater than $100 \mathrm{kHz}$.

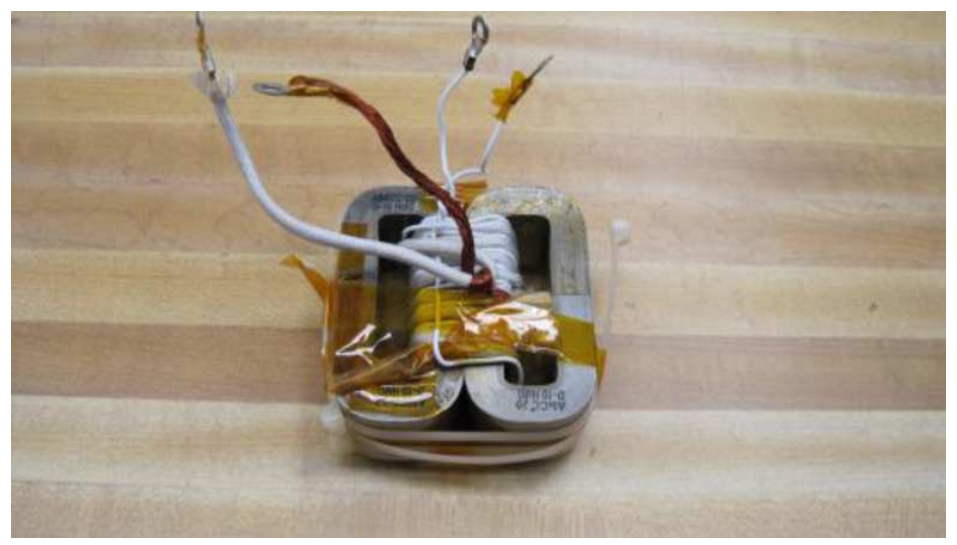

Figure 31. Experimental Inductor Built Using Two Sets of Metglas AMCC20 C Cores (The heavy gauge wires were used for the primary winding and the lighter gauge for the secondary winding. Turns ratio was 9:9.) 


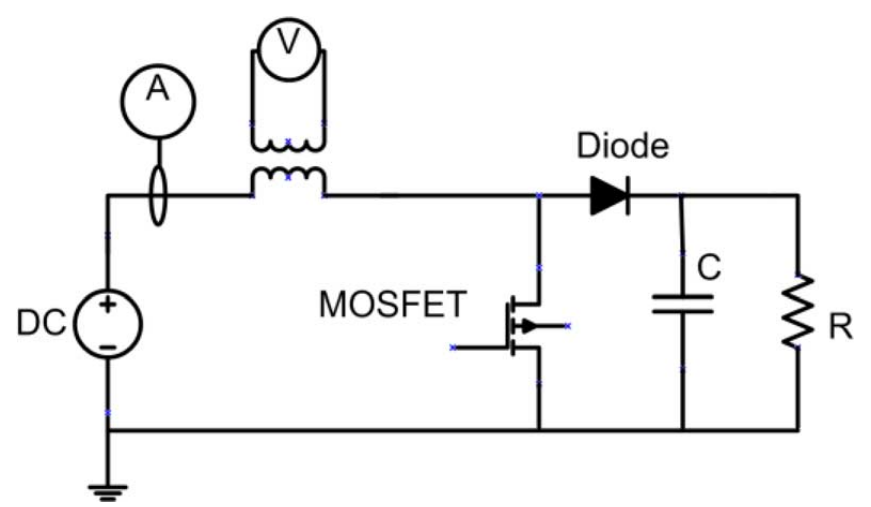

Figure 32. DC-DC Boost Converter Circuit

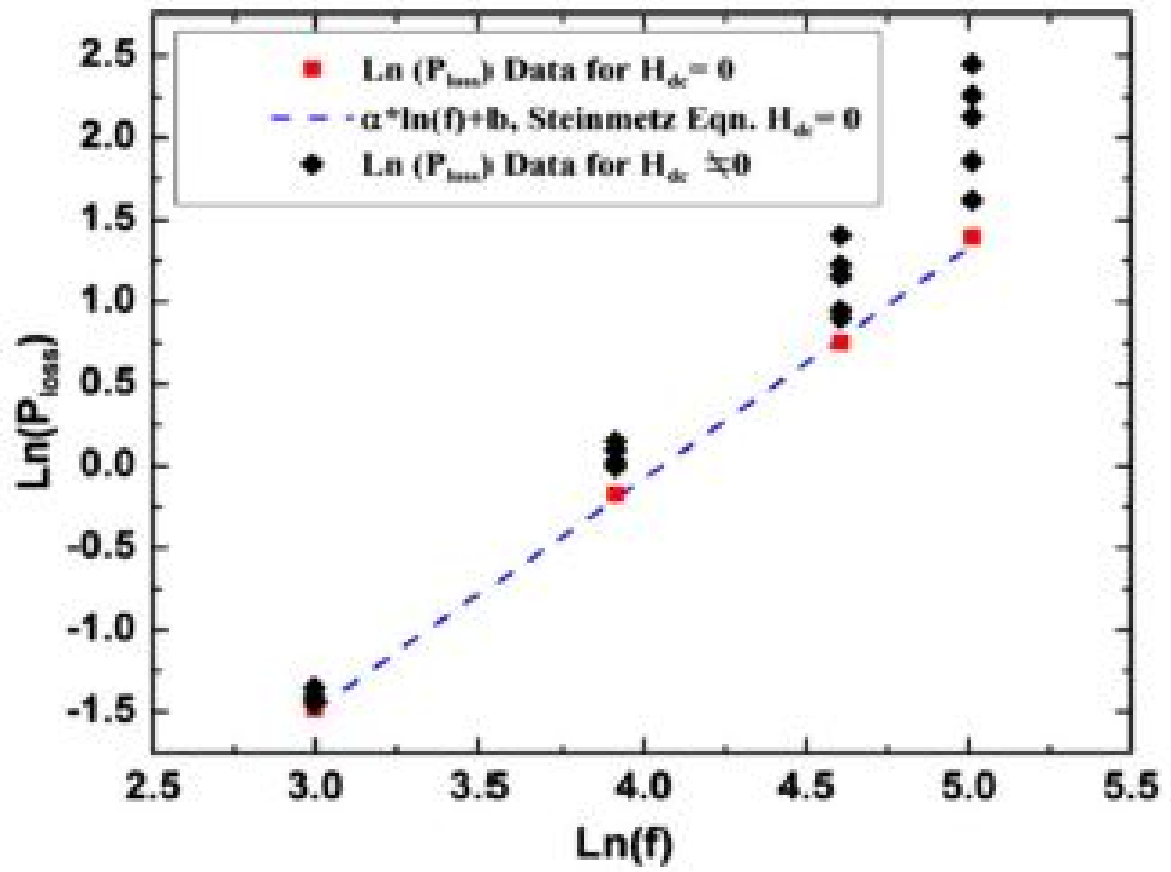

Figure 33. Loss Data Comparison 


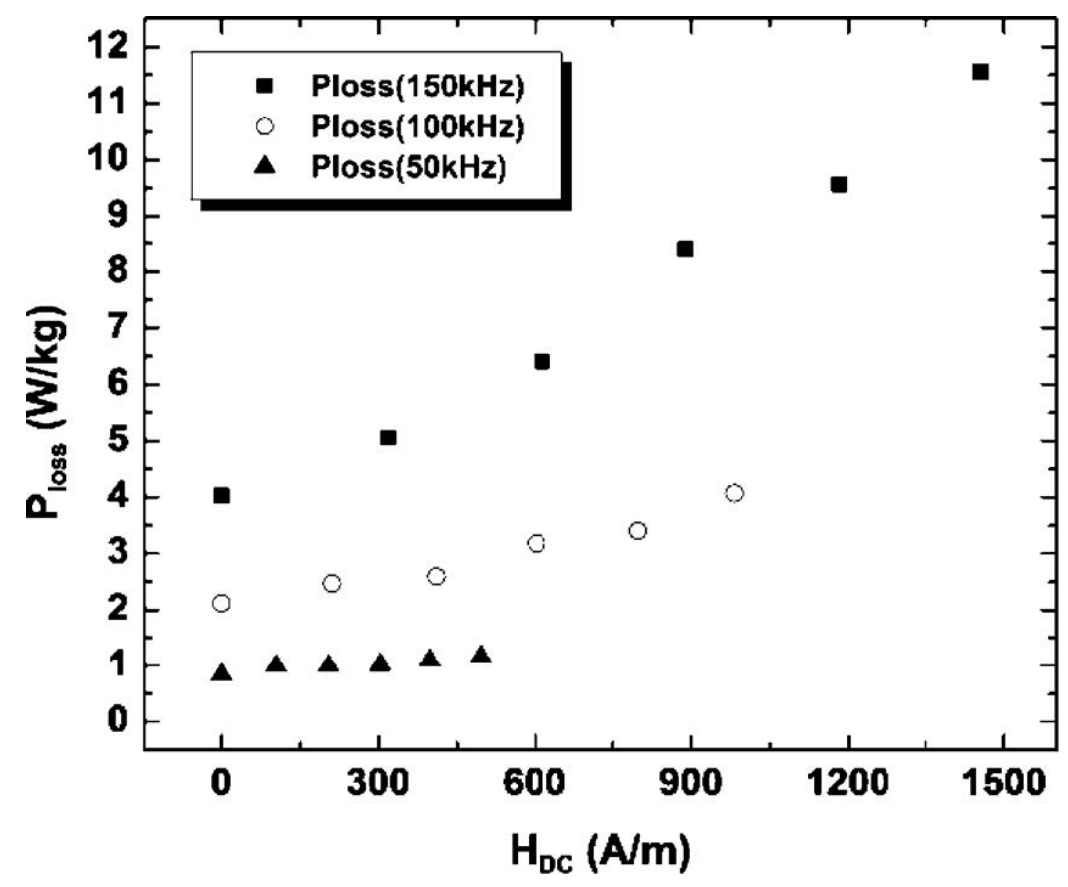

Figure 34. Power Loss Density vs. Pre-magnetization Fields ( $H_{D C}$ fields) for 150 , 100 , and 50 kHz Experimental Data 


\section{CONCLUSIONS}

Progress was made in several areas of magnetic materials and applications. Rare-earth powder and flake research has been promising with the production of materials with outstanding coercivities. Exchange-spring magnet research has produced smoothly coupled nanocomposite magnets, but energy products do not exceed existing rare-earth based magnets. Tape core material development has been promising but scale up issues remain.

Application successes include the modeling, fabrication, testing and patenting of a permanent magnet solenoid. Inductor DC-bias and loss characterizations also proved noteworthy. 


\section{RECOMMENDATIONS}

The development of new magnetic materials and applications is an on-going quest for research groups around the world. With the importance of magnetic materials, new superior and costeffective magnetic materials would have an easy transition into commercial and defense sectors.

The assumptions in the original exchange-spring paper by Kneller and Hawig should be revisited since research groups around the world have not yet produced greater energy products than existing neodymium rare-earth iron boron magnets.

Higher operating temperatures with high energy products should be researched. Optimization of tape cores for higher frequencies should also be pursued. Collaborative efforts throughout AFRL should be developed as needed. The optimization of magnetic devices for applications including converter and pulse power systems should be worked on. Electromachine research could be developed beyond just the current modeling efforts to include hardware demonstrations. 


\section{REFERENCES}

[1] B. D. Cullity, Introduction to Magnetic Materials, Reading: Addison-Wesley publishing company, 1972.

[2] N. C. Koon and B. N. Das, "Magnetic properties of amorphous and crystallized (Fe0.82B0.18)0.9T 0.05La0.05," Appl. Phys. Lett., vol. 39, no. 10, pp. 841-842, 1981.

[3] "Company History - A Timeline of Metglas History - Metglas, Inc.," [Online]. Available: http://metglas.com/metglas_company_history/. [Accessed 2015].

[4] S. J. Knutson, Y. Shen, J. C. Horwath, P. Barnes and C. H. Chen, "The effect of flake thickness on anisotropic SmCo5 nanoflakes/submicron-flakes with high energy product," $J$. Appl. Phys., vol. 109, no. 07A762, 2011.

[5] C. A. Crouse, E. Michel, Y. Shen, S. J. Knutson, B. K. Hardenstein, J. E. Spowart, S. O. Leontsev, S. L. Semiatin, J. Horwath, Z. Turgut and M. S. Lucas, "Effect of surfactant molecular weight on particle morphology of SmCo5 prepared by high energy ball milling," J. Appl. Phys., vol. 111, no. 07A724, 2012.

[6] S. Leontsev, M. Lucas, Y. Shen, A. Sheets, J. Horwath, E. Karapetrova and C. Crouse, "Surfactant Removal Study for Nano-Scale SmCo5 Powder Prepared by High Energy Ball Milling," IEEE Trans. Magn., vol. 49, no. 7, pp. 3341-3344, 2013.

[7] C. H. Chen, S. J. Knutson, Y. Shen, R. A. Wheeler, J. C. Horwath and P. A. Barnes, "The effect of particle size on coercivity and crystallinity of SmCo5," Appl. Phys. Lett., vol. 99, no. $012504,2011$.

[8] Y. Shen, M. Q. Huang, A. K. Higgins, S. Liu, J. C. Horwath, E. Karapetrova and C. Crouse, "Preparation of PrCo5 bulk magnets using nanograin powders made by surfactant-assisted high energy milling," J. Appl. Phys., vol. 107, no. 09A722, 2010.

[9] Y. Shen, M. Q. Huang, A. K. Higgins, S. Liu, J. C. Horwath and C. H. Chen, "PrCo5 Bulk Magnets Prepared Using Nanoflake Powders," in REPM'10 - Proceedings of the 21st Workshop on Rare-Earth Permanent Magnets and their Applications, 2010.

[10] E. F. Kneller and R. Hawig, "The Exchange-Spring Magnet: A New Material Principle for Permanent Magnets," IEEE Trans. Magn., pp. 3588-3600, 1991.

[11] Y. Shen, M. Q. Huang, Z. Turgut, M. S. Lucas, E. Michel and J. C. Horwath, "Effect of milling time on magnetic properties and structures of bulk $\mathrm{Sm}-\mathrm{Co} / \alpha-(\mathrm{Fe}, \mathrm{Co})$ nanocomposite magnets," J. Appl. Phys., vol. 111, no. 07B512, 2012.

[12] Y. Shen, S. O. Leontsev, Z. Turgut, M. S. Lucas, A. O. Sheets and J. C. Horwath, "“Effect of Soft Phase on Magnetic Properties of Bulk Sm-Co/ $\alpha-\mathrm{Fe}$ Nanocomposite Magnets," 
IEEE Trans. Magn., vol. 49, no. 7, pp. 3244-3247, 2013.

[13] M. Q. Huang, Z. Turgut, B. M. Ma, Z. M. Chen, D. Lee, A. Higgins, C. H. Chen, S. Liu, S. Y. Chu, J. C. Horwath and R. T. Fingers, "Effects of $\mathrm{Zr}, \mathrm{Nb}$, and $\mathrm{Cu}$ substitutions on magnetic properties of melt-spun and hot deformed bulk anisotropic nanocomposite SmCo type magnets," J. Appl. Phys., vol. 103, no. 07E134, 2008.

[14] C. H. Chen, A. K. Higgins, M. Q. Huang, J. C. Horwath, Y. Shen and S. Liu, "Bulk nanocrystalline $\mathrm{Sm}(\mathrm{Co} 1-\mathrm{xFex}) \mathrm{z}$ with $\mathrm{z}$ up to $14.7 \%$ and $35 \% \mathrm{Co}-\mathrm{Fe}$ phase and the effect of fluorine inclusion," J. Appl. Phys., vol. 105, no. 07A718, 2009.

[15] Y. Shen, Z. Turgut, J. Horwath and M. Huang, "Bulk nanocomposite LaCo5/LaCo13 magnets," J. Appl. Phys., vol. 109, no. 07A765, 2011.

[16] Z. Turgut, M. Huang, J. C. Horwath and R. T. Fingers, "High strength bulk Fe-Co alloys produced by powder metallurgy," J. Appl. Phys., vol. 103, no. 07E724, 2008.

[17] Z. Turgut, J. C. Horwath, M. Huang and J. E. Coate, "Isothermal oxidation behaviors of FeCoV and FeCoVNb alloys," J. Appl. Phys., vol. 105, no. 07A330, 2009.

[18] M. S. Lucas, W. C. Bourne, A. O. Sheets, L. Brunke, M. D. Alexander, J. M. Shank, E. Michel, S. L. Semiatin, J. Horwath and Z. Turgut, "Nanocrystalline Hf and Ta containing FeCo based alloys for high frequency applications," Materials Science and Engineering B, vol. 176, pp. 1079-1084, 2011.

[19] Z. Turgut, L. Christy, H. M. and J. C. Horwath, "Effect of copper addition on crystallization and properties of hafnium containing HITPERM alloys (invited)," J. Appl. Phys., vol. 107, no. 09A327, 2010.

[20] M. S. Lucas, D. Belyea, C. Bauer, N. Byrant, E. Michel, Z. Turgut, S. O. Leontsev, J. Horwath, S. L. Semiatin, M. E. McHenry and C. W. Miller, "Thermomagnetic analysis of FeCoCr x Ni alloys: Magnetic entropy of high-entropy alloys," J. Appl. Phys., vol. 113, no. 17A923, 2013.

[21] M. S. Lucas, G. B. Wilks, L. Mauger, J. A. Muñoz, O. N. Senkov, E. Michel, J. Horwath, S. L. Semiatin, M. B. Stone, D. L. Abernathy and E. Karapetrova, "Absence of long-range chemical ordering in equimolar FeCoCrNi," Appl. Phys. Lett., vol. 100, no. 251907, 2012.

[22] M. S. Lucas, L. Mauger, J. A. Muñoz, Y. Xiao, A. O. Sheets, S. L. Semiatin, J. Horwath and Z. Turgut, "Magnetic and vibrational properties of high-entropy alloys," J. Appl. Phys., vol. 109, no. 07E307, 2011.

[23] M. S. Lucas, J. A. Muñoz, L. Mauger, C. W. Li, O. S. A., Z. Turgut, J. Horwath, D. L. Abernathy, M. B. Stone, O. Delaire, Y. Xiao and B. Fultz, "Effects of chemical composition and B2 order on phonons in bec Fe-Co alloys," J. Appl. Phys., vol. 108, no. 023519, 2010. 
[24] M. S. Lucas, L. Mauger, J. A. Munoz, I. Halevy, J. Horwath, S. L. Semiatin, S. O. Leontsev, M. B. Stone, D. L. Abernathy, Y. Xiao, P. Chow and B. Fultz, "Phonon densities of states of face-centered-cubic Ni-Fe alloys," J. Appl. Phys., vol. 113, no. 17A308, 2013.

[25] M. S. Lucas, J. A. Muñoz, O. Delaire, N. D. Markovskiy, M. B. Stone, D. L. Abernathy, I. Halevy, L. Mauger, J. B. Keith, M. L. Winterrose, Y. Xiao, M. Lerche and B. Fultz, "Effects of composition, temperature, and magnetism on phonons in bec Fe-V alloys," Physical Review B, vol. 82, no. 144306, 2010.

[26] M. S. Lucas, "Phonon thermodynamics of binary Fe alloys," in TMS Annual Meeting \& Exhibition, Supplemental Procedings, 2011.

[27] B. W. Hoff, C. H. Chen, J. C. Horwath, M. D. Haworth, P. J. Mardahl and S. L. Heidger, "Wide aperture permanent magnet solenoid," J. Appl. Phys., vol. 111, no. 07A711, 2012.

[28] C. H. Chen, S. Lin, J. C. Horwath, B. W. Hoff, M. D. Haworth and S. L. Heidger, "Effect of surrounding air region size on finite element modeling for permanent magnetic solenoids," J. Appl. Phys., vol. 109, no. 07A757, 2011.

[29] H. Kosai, S. McNeal, B. Jordan, J. Scofield, B. Ray and Z. Turgut, "Coupled Inductor Characterization for a High Performance Interleaved Boost Converter," IEEE Trans. Magn., vol. 45, no. 10, pp. 4812-4815, 2009.

[30] H. Kosai, Z. Turgut and J. Scofield, "Experimental Investigation of DC-Bias Related Core Losses in a Boost Inductor," IEEE Trans. Magn., vol. 49, no. 7, pp. 4168-4171, 2013. 